The submitted manuscript has been authored by a contractor of the U.S. Government under contract No. W-31-109-ENG-38.

Accordingly, the U.S. Government retains a

nonexclusive, royalty-free license to publish

or reproduce the published form of this

contribution, or allow others to do so, for

U. S. Government purposes.

\title{
The APS Beamline Front End Vacuum System
}

\author{
R. W. Nielsen \\ Experimental Facilities Division
}

October 15, 1993

\author{
Advanced Photon Source \\ Argonne National Laboratory
}




\title{
The APS Beamline Front End Vacuum System
}

\author{
Robert W. Nielsen
}

October 13, 1993

\section{Argonne National Laboratory}

\section{Advanced Photon Source}

\section{Experimental Facilities Division}

\author{
DISCLAIMER
}

This report was prepared as an account of work sponsored by an agency of the United States Government. Neither the United States Government nor any agency thereof, nor any of their employees, makes any warranty, express or implied, or assumes any legal liability or responsibility for the accuracy, completeness, or usefulness of any information, apparatus, product, or process disclosed, or represents that its use would not infringe privately owned rights. Reference herein to any specific commercial product, process, or service by trade name, trademark, manufacturer, or otherwise does not necessarily constitute or imply its endorsement, recommendation, or favoring by the United States Government or any agency thereof. The views and opinions of authors expressed herein do not necessarily state or reflect those of the United States Government or any agency thereof. 


\section{DISCLAIMER}

Portions of this document may be illegible in electronic image products. Images are produced from the best available original document. 
Table of Contents

$\begin{array}{ll}\text { Acknowledgements } & \text { ii } \\ \text { Introduction } & 1 \\ \text { Vacuum Calculations } & 2 \\ \text { Differential Pump } & 6 \\ \text { Front Fnd Vacuum Set Points . } & 7 \\ \text { Cleaning wethods and Agents } & 7 \\ \text { RED Completed } & 9 \\ \text { Continuing RED } & 10 \\ \text { References } & 12\end{array}$




\section{Acknowledgements}

I would like to acknowledge the following for their help and support in preparation of this paper:

Try Leng Kruy for his hard work, suggestions, and experience in the lab where he has assembled and tested the vacuum systems during the past year.

Deming shu for his design work of the front end components and the interface to the vacuum components.

The entire design and drafting staff for their drawings and patience during the many changes required to reach the present design.

John wammack for his efforts in preparing data acquisition systems for the lab work as well as final testing of finished components.

Lester shirkey for his efforts in designing bakeout and power systems for the vacuum bake cycle.

Dave Ryding for his work on special materials, e.g.,tungsten and glidcop to be used in the vacuum system.

Jeff Collins for engineering and coordinating the construction of the clean room facility and to Dave Travis and Dan Nocher for the actual construction.

The members of the Front End Value Engineering Workshop for their recommendations enabling the accomplishment of the desired vacuum criteria more economically.

Tuncer Kuzay for his guidance, constructive criticism, and encouragement. 


\section{THE APS BEAMLINE ERONT END VACUUM SYSTEM}

\section{Introduction}

The APS beamline front ends are designed to be standard, one type for all planned insertion devices (IDs) and another type for all bending magnets (BMs). Depending on the ID source power and user needs, the ID front ends can be of windowless operation (with the use of differential pumps) or of conventional window operation. Figures 1,2, and 3 are drawings of the front end layout for (1) a bending magnet front end, (2) an insertion device front end and (3) a windowless insertion device front end showing the placement of pumps, valves, and required front end hardware. A fast valve is used to protect the storage ring vacuum from the shock wave associated with a massive vacuum breach in the downstream front end or in the downstream beam line proper. This valve is preceded by an all-metal gate valve, which will start to close at the same time the fast valve is triggered. This will isolate the upstream front end and the storage ring vacuum from any further pressure increase caused by downstream vacuum breaches.

Because all the front ends are directly coupled to the storage ring vacuum system, the upstream front end vacuum requirements equal those of the storage ring. This requires a pressure of less than 1 nTorr with beam on. Achieving UHV 
vacuum conditions requires that hydrocarbons and contaminants be kept to a minimum. The pumping system will consist of portable dry (oil-free) mechanical pumps backing turbomolecular pumps for roughing the system down and permanently mounted ion pumps with nonevaporable getter capabilities providing the final UHV pumping. Information on UHV pressure will be monitored through the use of nude UHV ion gauges located at upstream and downstream front end locations, and higher pressure information will be obtained through the use of convectron gauges located between the fast and slow valve and on the portable roughing carts. Mass spectra will also be monitored at the upstream end of the front ends, where an RGA will be installed.

\section{Vacuun Calculations}

The design of the front end vacuum has utilized the finite element analysis computer program developed at Argonne to model and optimize the front end vacuum characteristics. The thermal desorption used for these vacuum calculations is $3 \times 10^{-12} \mathrm{Tl} / \mathrm{sec} / \mathrm{cm}^{2}$, and the synchrotron-radiation-induced desorption coefficient is $1 \times 10^{-6}$ molecules/photon after 500 hours of operation with 100 ma circulating positron current in the storage ring. The above thermal desorption value is a standard number used for clean, baked stainless steel. (1) The desorption coefficient ( $1 \times 10^{-6}$ mol/photon) is a reasonably attainable value as 
agreed upon at an international workshop held at Cornell University. (2) The selection and placement of pumps, valves, and bakeout and monitoring equipment are based on the results of the computer analysis.

Figure 1.1 is a bending magnet front end vacuum profile generated by the computer vacuum program depicting $100 \%$ of the beam interacting with fixed mask 1 . This condition could exist only if gross beam missteering were to occur in the storage ring. It is a worst-case scenario that would be of very short duration because the beam diagnostic feedback system would dump the stored beam.

Figure 1.2 is a bending magnet front end vacuum profile with $10 \%$ of the beam interacting with fixed mask 1 and $90 \%$ of the beam stopped by shutter 1. This would be the condition of a long-term shutdown of a bending magnet beamline.

Figure 1.3 is a bending magnet front end vacuum profile with $10 \%$ of the beam interacting with fixed mask $1,10 \%$ of the beam interacting with fixed mask 2, and $80 \%$ of the beam stopped by shutter 2. This would be the condition when users would enter a hutch or beamline area requiring beam to be shut down during entry.

Figure 1.4 is a bending magnet front end vacuum profile with 108 of the beam interacting with fixed mask 1, $10 \%$ of the beam interacting with fixed mask 2, $15 \%$ interacting with the filters, $10 \%$ interacting with the window assembly, and the remainder transported downstream to the user. 
From the above (4) examples it can be observed that the necessary vacuum requirements are met in all cases with the exception of that shown in Eigure 1.1 in which the upstream vacuum could exceed $1 \times 10^{-9}$ Torr for a short time until the beam position feedback system either corrects the missteering or shuts down the beam.

Figure 2.1 is an insertion device front end vacuum profile with $100 \%$ of the beam interacting with fixed mask 1 . This condition could exist only if gross beam missteering were to occur in the storage ring. It is a worst-case scenario that would be of very short duration because the beam diagnostic feedback system would dump the stored beam.

Figure 2.2 is an insertion device front end vacuum profile with 18 of the beam interacting with fixed mask 1 and 998 of the beam stopped by shutter 1 . This would be the condition of a long-term shutdown of an insertion device front end.

Figure 2.3 is an insertion device front end vacuum profile with 18 of the beam interacting with fixed mask 1 , $1 \%$ interacting with fixed mask 2 , and $98 \%$ of the beam stopped on shutter 2 . This would be the condition during which users would enter hutches or other areas requiring beam to be off.

Figure 2.4 is an insertion device front end vacuum profile with 18 of the beam interacting with each of fixed masks 1 and 2, $3 \%$ interacting with shutter 2, $5 \%$ interacting 
with the filters, $1.5 \%$ interacting with the exit window, and the remainder transported to the users.

From the above (4) examples it can be observed that the necessary vacuum requirements are met in all cases with the exception of that shown in Figure 2.1 in which the upstream vacuum could exceed $1 \times 10^{-9}$ Torr for a short time until the beam position feedback system either corrects the missteering or shuts down the beam.

Figure 3.1 is a windowless insertion device front end vacuum profile with the same conditions as in Figure 2.1 above.

Figure 3.2 is a windowless insertion device front end vacuum profile with the same conditions as in Figure 2.2 above.

Figure 3.3 is a windowless insertion device front end vacuum profile with conditions equal to those in Figure 2.3 above.

Figure 3.4 is a windowless insertion device front end vacuum profile with conditions similar to those in Figure 2.4 above. The difference is due to the differential pump negating the need for filters and the window assemblies. The beam interaction with these components is eliminated.

From the above (4) examples it can be observed that the necessary vacuum requirements are met in all cases with the exception of that shown in Figure 3.1 in which the upstream vacuum could exceed $1 \times 10^{-9}$ Torr for a short time until the 
beam position feedback system either corrects the missteering or shuts down the beam.

\section{Differential Pump}

Figure 4 is a diagram of the standard differential pump designed for APS operation. Using apertures of $10 \mathrm{~mm} x$ $78 \mathrm{~mm}, 12 \mathrm{~mm} \times 78 \mathrm{~mm}$ and $14 \mathrm{~mm} \times 78 \mathrm{~mm}$ (as shown in the drawing), pressure differentials of greater than two orders of magnitude have been obtained. An added benefit has been the time delay observed when producing a high pressure burst at the downstream end of the pump and measuring the time before the pressure increase is detected on the upstream end of the pump. Figure 5 is a plot showing this measured delay when allowing the downstream pressure to rise rapidly from $2.4 \mathrm{x}$ $10^{-7}$ Torr to $1 \times 10^{-4}$ Torr. A delay in excess of $100 \mathrm{msec}$ is evident. Other delays are engineered into the front ends in the form of small apertures on each side of large volume chambers. Figures 6 and 7 show the aperture sizes and locations for an insertion device front end and a front end specicifically for undulators, respectively. Formal delay line tubes are included in the bending magnet front end as well as in the windowless insertion device front end. No space is available for a formal delay line in the conventional window-type insertion device front end. 


\section{Front Fnd Vacuum Set Points}

All front ends are equipped with valving and vacuum sensing to protect the storage ring vacuum in the event of a severe vacuum breach in a beamline. Figure 8 is a diagram showing the logic and set points used to control three valves (SV, slow valve), (EV, fast valve) and (EV, exit valve) to protect and isolate various sections of the frontend and the storage ring. In order for the EV to open, the pressure downstream of the differential pump must be $<1 \times$ $10^{-6}$ Torr, and the pressure upstream of the differential pump must be $<1 \times 10^{-8}$ Torr, and the pressure in the safety shutter chamber must be $<6 \times 10^{-9}$ Torr. Any one of the three pressures exceeding their set point will cause the EV to close or prevent it from opening. If the pressure upstream of the EV reaches $1 \times 10^{-8}$ Torr or higher, the SV will close as will shutter 1 to prevent beam from damaging the valve. If the pressure upstream of the EV reaches or exceeds $1 \times 10^{-5}$ Torr, the SV and the EV will close and beam in the storage ring will be dumped. This will happen only if a serious pressure problem exists in the beamline.

\section{cleaning Methods and Agents}

New cleaning techniques have been investigated to comply with ES\&H and to reduce cleaning waste and residue, disposal of which is very expensive. One product tested is 
Citronox, which is a citric-acid-based product and can be disposed of by flushing down the drain. This product has been used in a $5 \%$ solution with DI water at 55 deg. C to clean copper and glidcop samples. A 15-minute bath in

Citronox has cleaned these materials but has left a brownish oxide layer, which was removed by scrubbing with scotchbrite pads with trichlor, acetone, and methanol. Glidcop processed in this manner has been installed in a vacuum system and pumped into the mid $10^{-11}$ Torr range with no undesirable traces detected on an RGA.

A novel method of cleaning using supercritical $\mathrm{CO}_{2}$ has been examined with some encouraging résults. (3) Supercritical cleaning relates to the properties of gas liquification. If a pure gas is compressed below a "critical temperature," liquification occurs. At temperatures above the critical temperature no liquification is possible regardless of the pressure applied. Figure 9 is a phase diagram of a typical supercritical fluid. For $\mathrm{CO}_{2}$, the critical temperature is 31 deg. $C$ and the critical pressure is 1073 psi. As the pressure is increased, the gas density increases to near-liquid density at which point the supercritical fluid displays good solubilizing properties. The cleaning effectiveness of supercritical $\mathrm{CO}_{2}$ is dependent on the temperature, pressure, flow rate, turbulence, and time left in the media. The bottom diagram in Figure 9 is a schematic of a supercritical cleaning system. Samples of 
stainless steel, copper, and glidcop were cleaned with this method, and the results compared with cleaning in trichlor, acetone, and methanol using ultrasonics. Figure 10 is a sample ESCA plot, which was the method used to analyze the results. Figure 11 is a chart of the results showing that the chemical cleaning results are somewhat better than the supercritical results. During the supercritical cleaning, the flow rate was so low that no turbulence was present. It is believed that increasing the flow rate and adding ultrasonics or agitation could improve the effectiveness of this cleaning method. Testing will continue.

\section{RED Completed}

Testing has been completed on a $4^{\prime \prime}$ fast valve of the type to be used to protect the storage ring vacuum from vacuum breaches in a beamline or downstream front end. The top diagram of Figure 12 shows the experimental setup used to test the valve closing time. A laser was directed through the windows on each side of the valve to a detector on the opposite side of the valve. The center plot of Figure 12 is an oscilloscope trace showing the closing time $(6.3 \mathrm{msec})$ when the valve was closed by pushing the close button on the controller. The bottom plot of Figure 12 shows the closing time when the pressure was increased above the set point in the chamber containing the valve pressure sensor (cold 
cathode gauge). The closing time was $6.76 \mathrm{msec}$. Well over 100 cycles were run with no apparent change in closing time. Work has been done on developing a UHV-compatible tungsten in which porosity is minimized to reduce thermal desorption gas loads. Measurements of tungsten outgassing has been done at Berkeley at the ALs. (4) The results from Berkeley were $.87 \mathrm{nTorr} 1 / \mathrm{sec} / \mathrm{cm}^{2}$ from an $85 \mathrm{~cm}^{2}$ surface area sample. The sample measured at the APS using a $690 \mathrm{~cm}^{2}$ sample yielded a $.22 \mathrm{nTorr} 1 / \mathrm{sec} / \mathrm{cm}^{2}$ thermal desorption. The desorption for clean baked stainless steel is .01 nTorr $1 / \mathrm{sec} / \mathrm{cm}^{2}$. The sample used at the APS was type HD18DS from Mi-Tech Metals. This sample was first cleaned by scrubbing with Scotchbrite in trichlor, acetone, and methanol and was then cleaned ultrasonically in each of these agents for 15 min. This block of tungsten was put in a vacuum system and pumped to $6 \times 10^{-11}$ Torr with no adverse elements in the RGA spectra. Comparable samples have also been supplied by Kulite Corp. Both manufacturers now supply UHV-grade tungsten.

\section{Continuing R\&D}

A full-scale prototype windowless front end is being constructed and assembled in the building 362 high bay where several vacuum as well as other tests will be conducted. Planned vacuum tests include (1) determination of front end roughing time and pump-down time, (2) measurement of the 
front end vacuum profile, (3) shock-wave delay measurements and (4) measurement of the pressure in the upstream frontend area after breaking a downstream window and allowing the entire safety system (FV, SV, etc.) to shut down the front end vacuum system. 


\section{References}

1. A. Roth, Vacuum Technology (Second Edition) p.144

2. "Workshop Summaries from the International Workshop on Vacuum Systems for B-Factories and High-Energy Synchrotron Light Sources, " Cornell University, January 16 - 18, 1992, CLNS92/1134

3. R. Nielsen and T.M.Kuzay, "Preliminary Cleaning Tests on Candidate Materials for APS Beamline and Front End Components," May 12, 1992, LS-197

4. Thomas Swain, "UHV Issues for Tungsten Radiation Stops," March 4, 1991, AL-20-15 

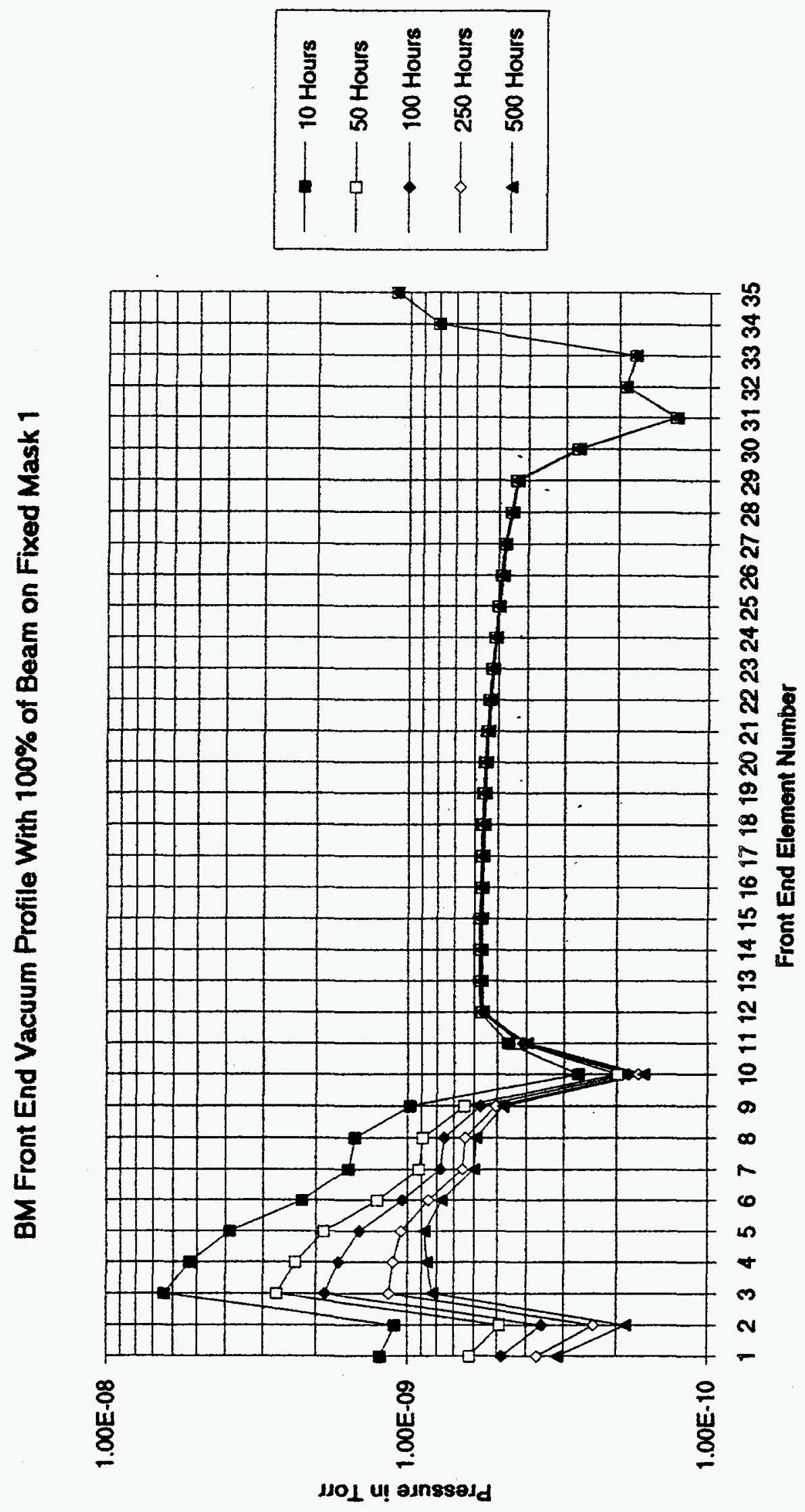

훙 

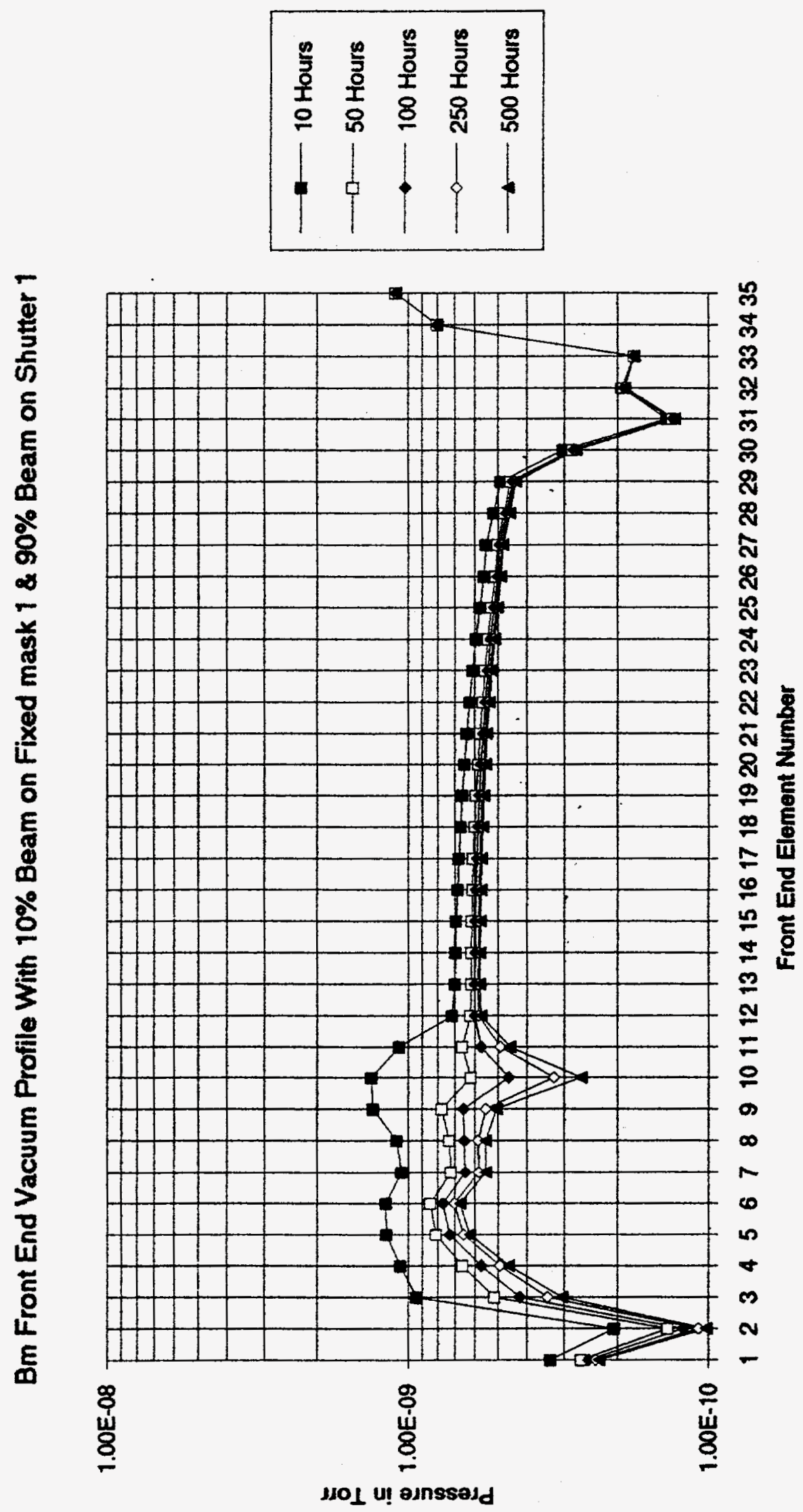

率 
BM Front End Vacuum Profile With 10\% Beam on FM1, 10\% Beam on FM2, \& 80\% Beam on Shutter 2

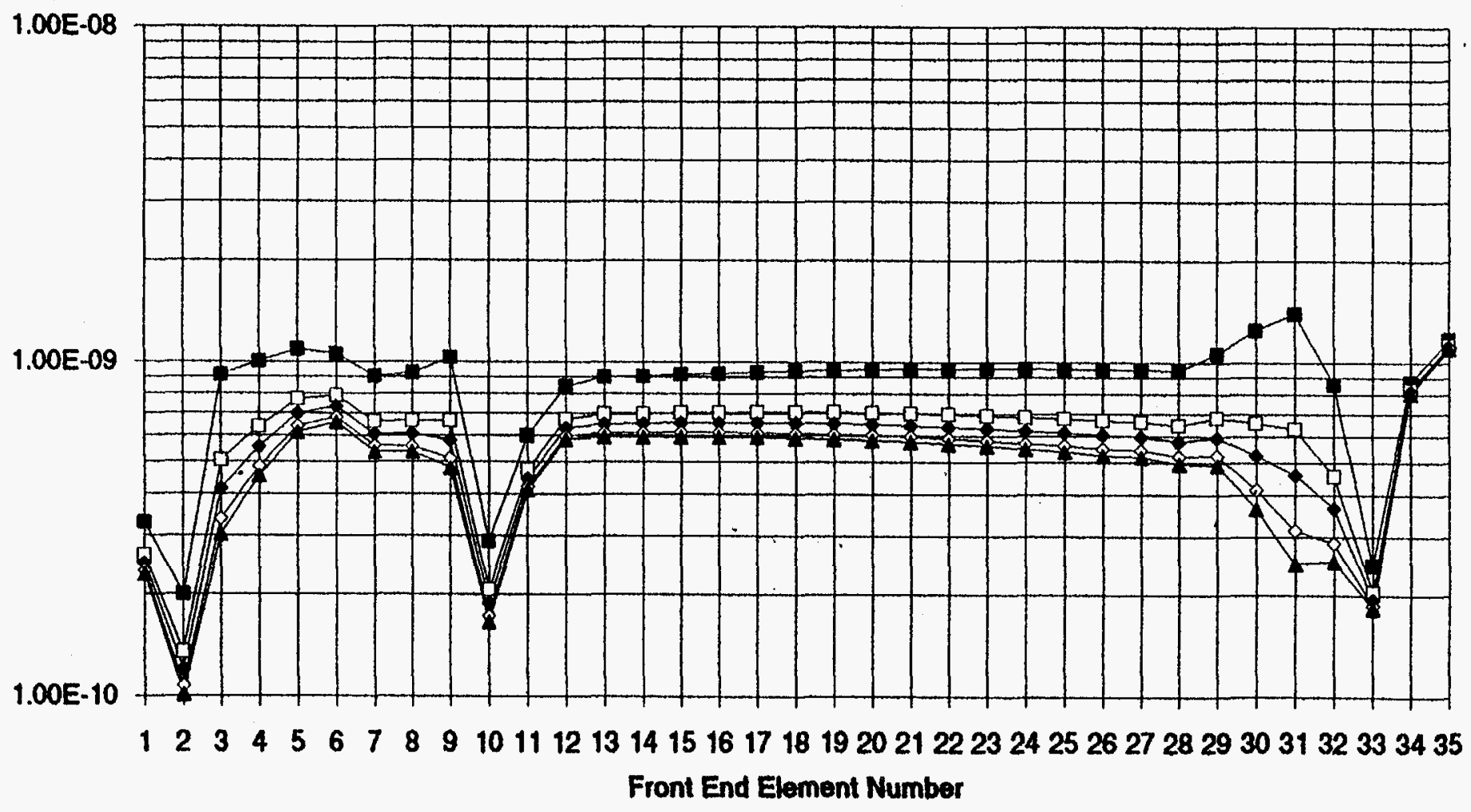

$$
\begin{array}{r}
\longrightarrow \\
\square
\end{array}
$$

Front End Element Number 


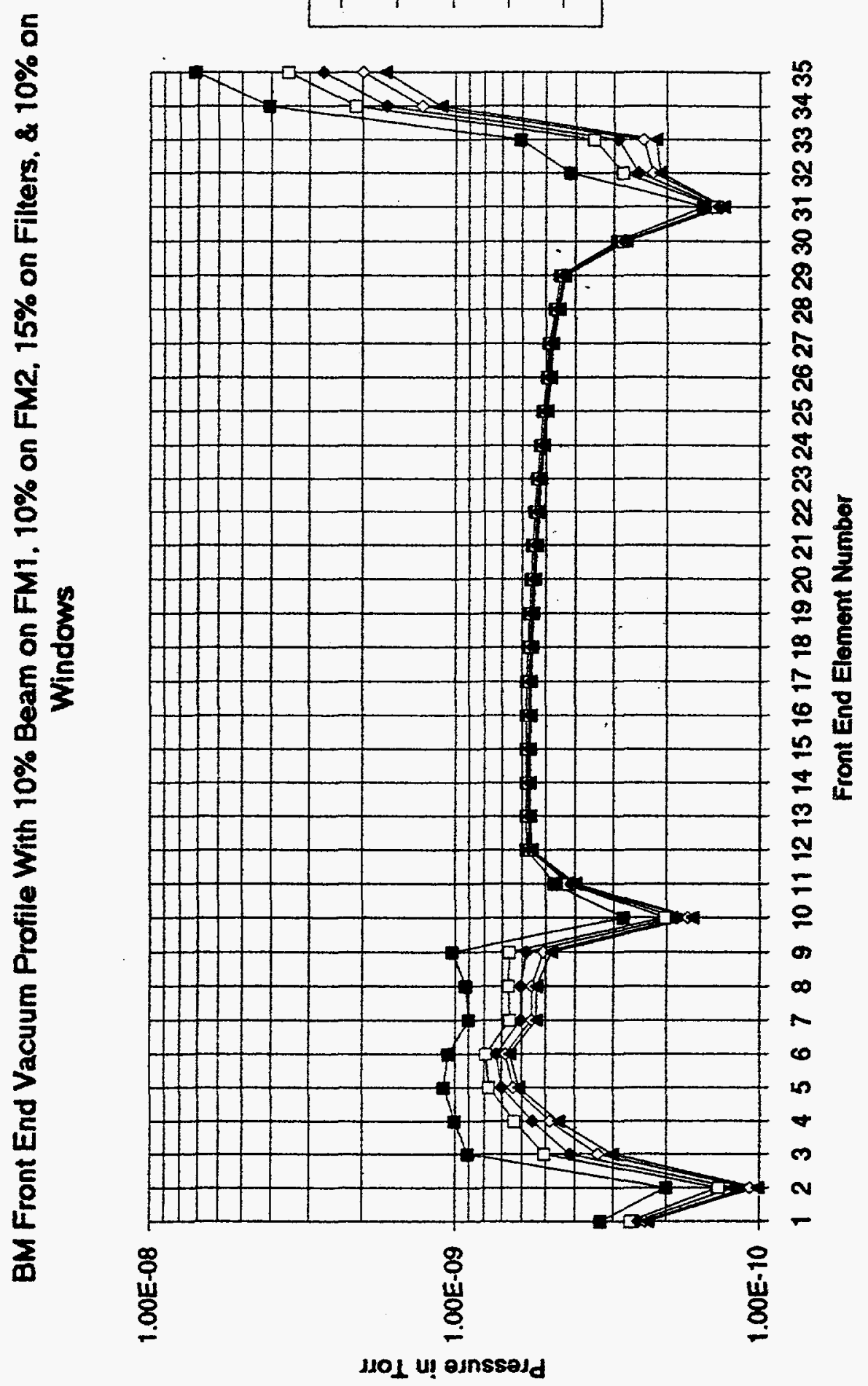




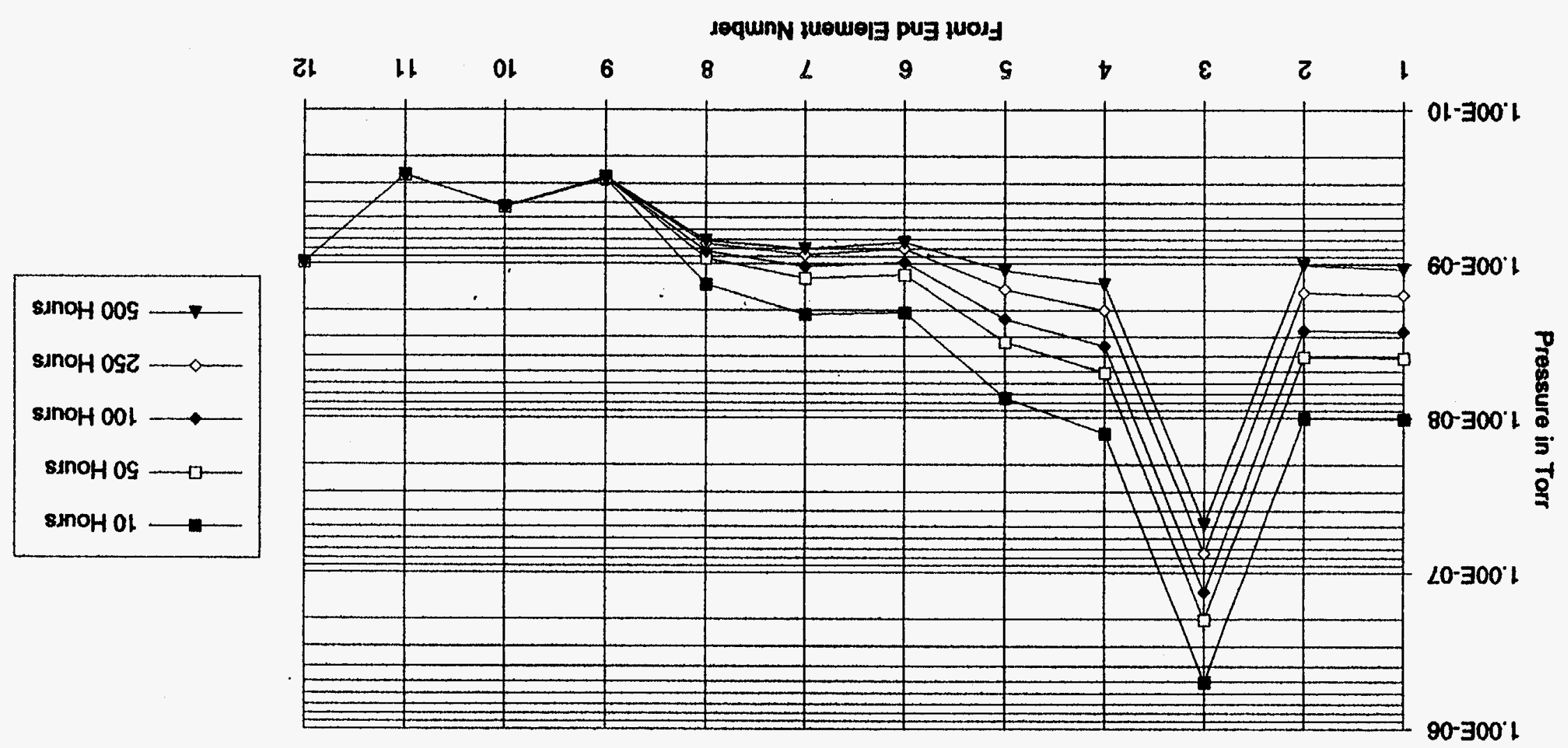

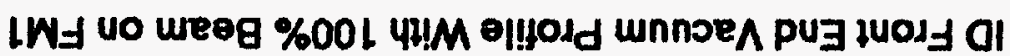


ID Front End Vacuum Profile With 1\% Beam on FM1 \& 99\% Beam on Shutter 1

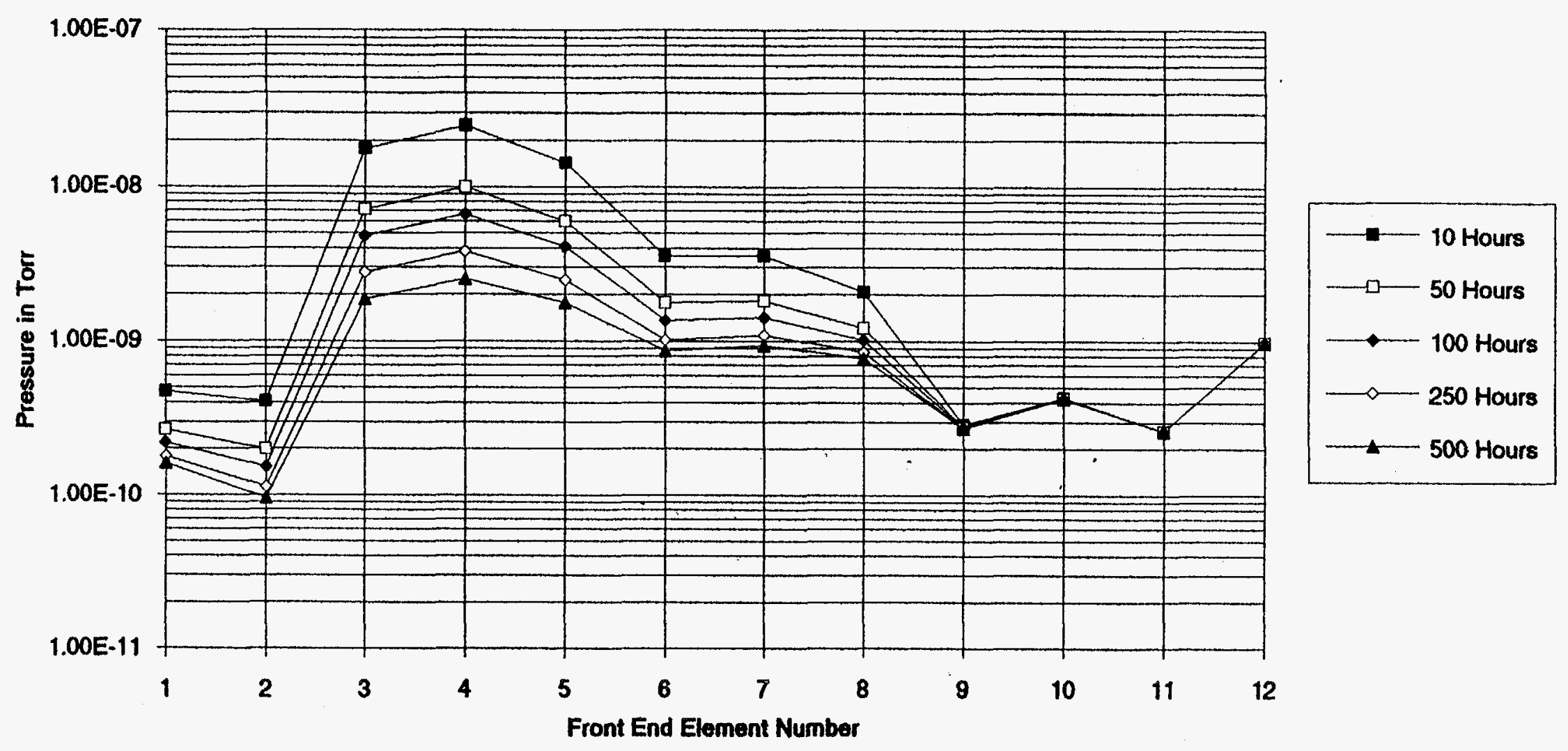


ID Front End Vacuum Profile With 1\% Beam on FM1, 1\% Beam on FM2, \& 98\% Beam on Shutter 2

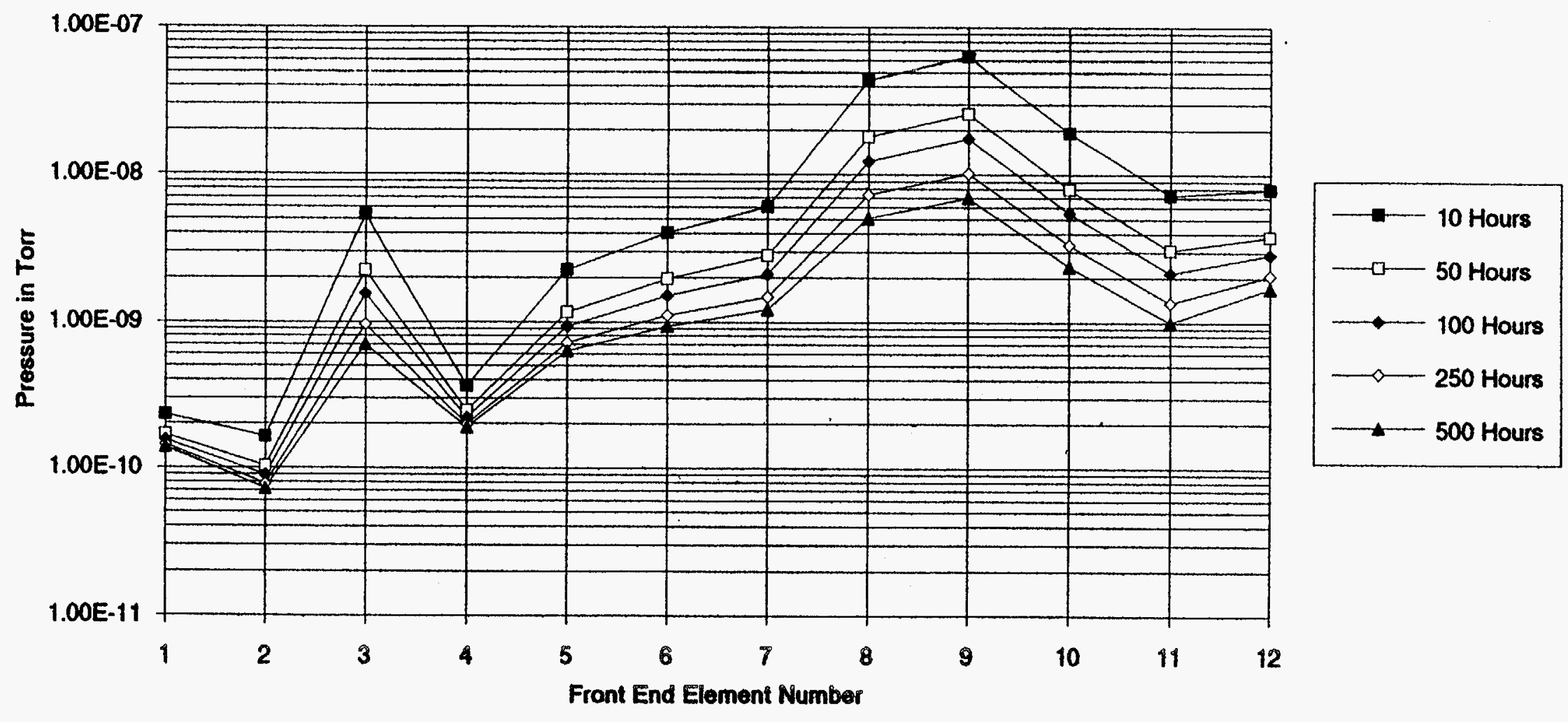


ID Front End Vacuum Profile With 1\% Beam on FM182, 3\% Beam on Shutter 2, 5\% Beam on Filters. \& 1.5\% Beam on Exit Window

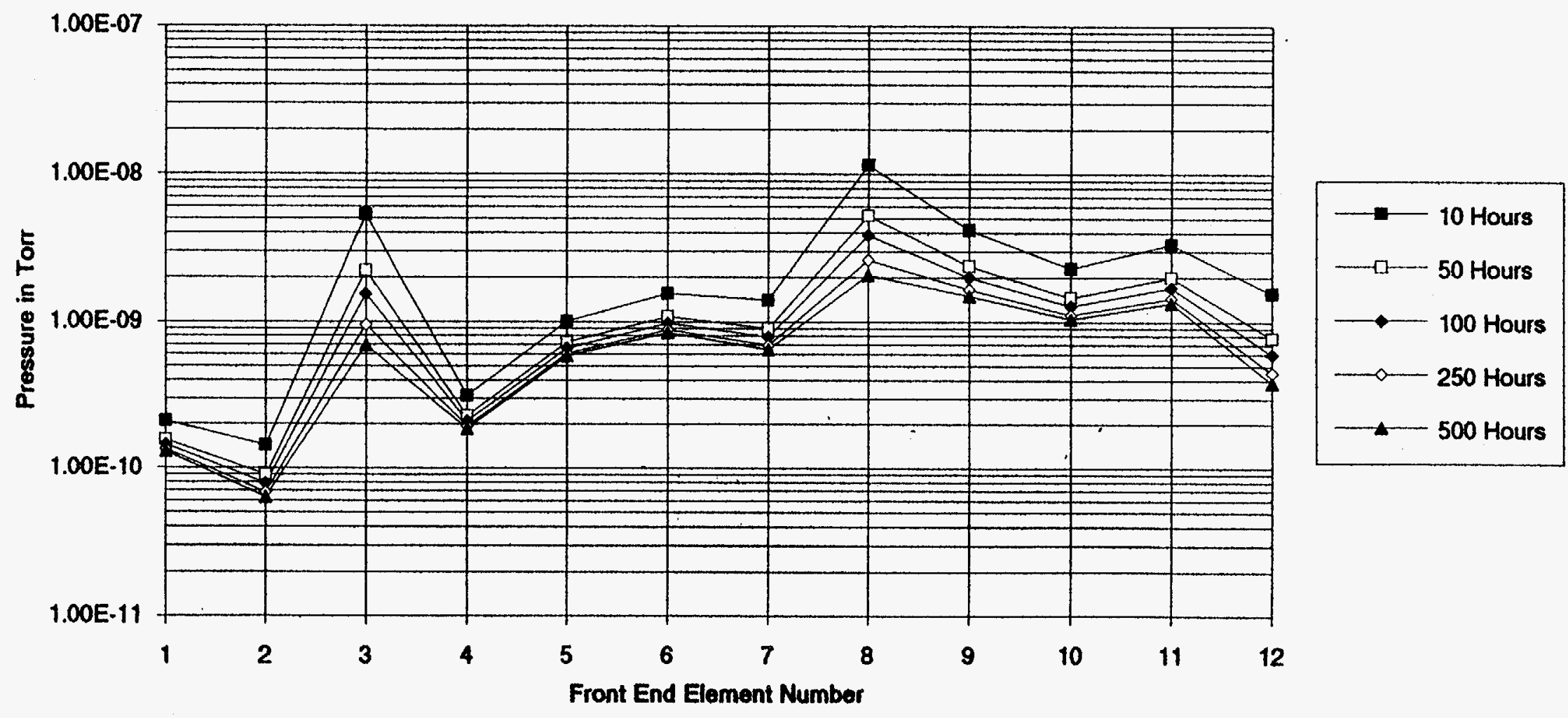


Windowless ID Front End Vacuum Profile With $100 \%$ of Beam on FM1

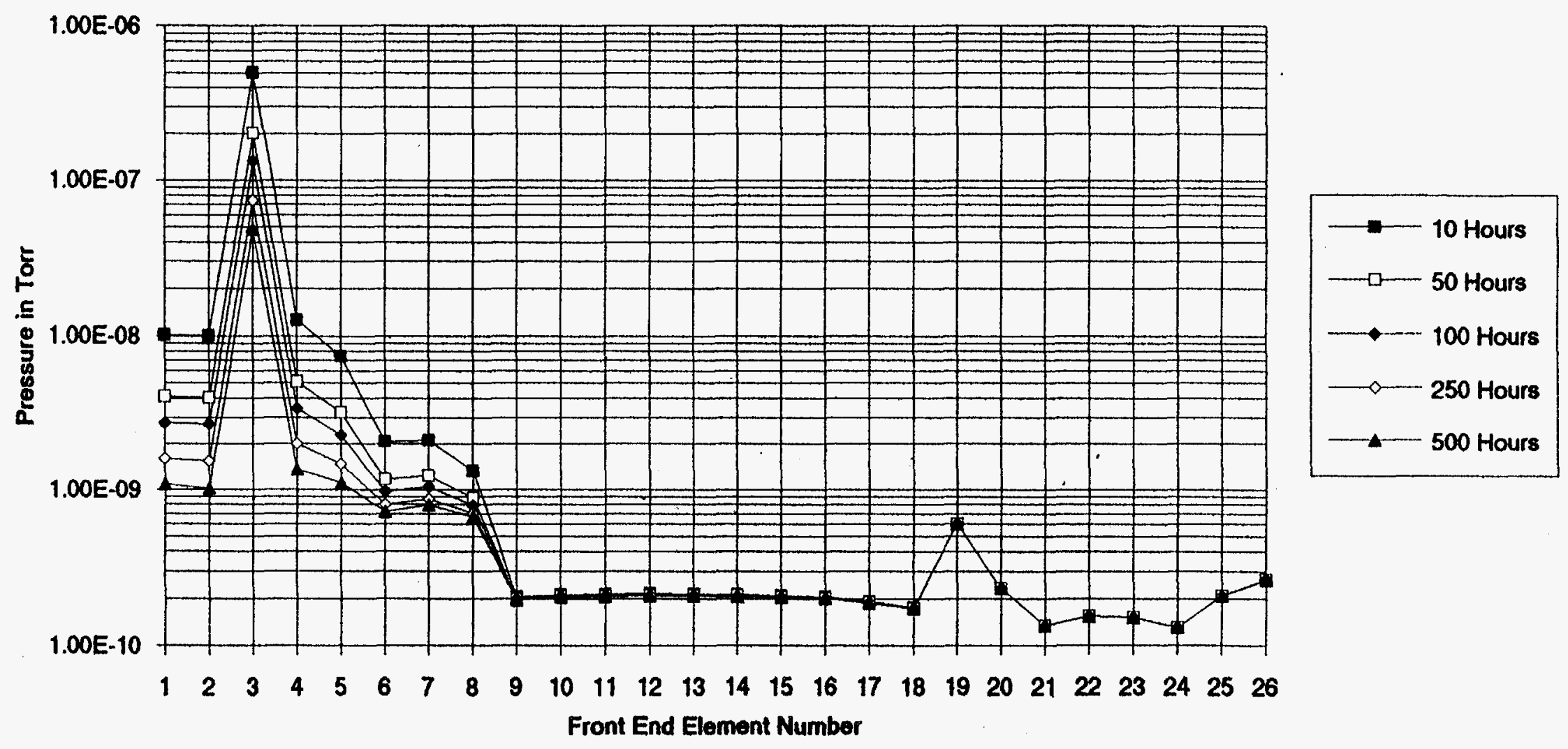


Windowless ID Front End Vacuum Profile With 1\% Beam on FM1 \& 99\% Beam on Shutter 1

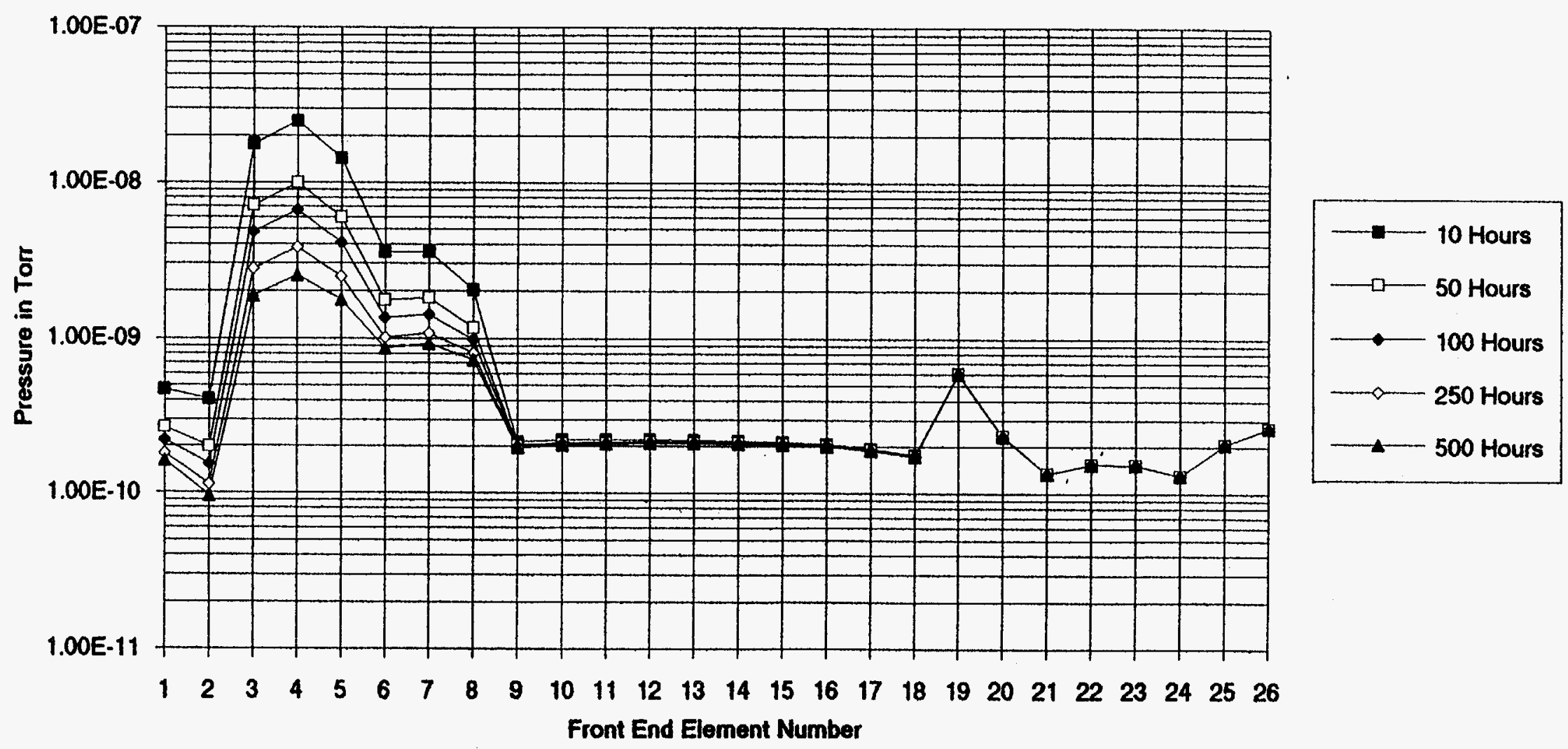


Windowless ID Front End Vacuum Profile With 1\% Beam on FM1. 1\% Beam on FM2, \& $98 \%$ Beam on Shutter 2

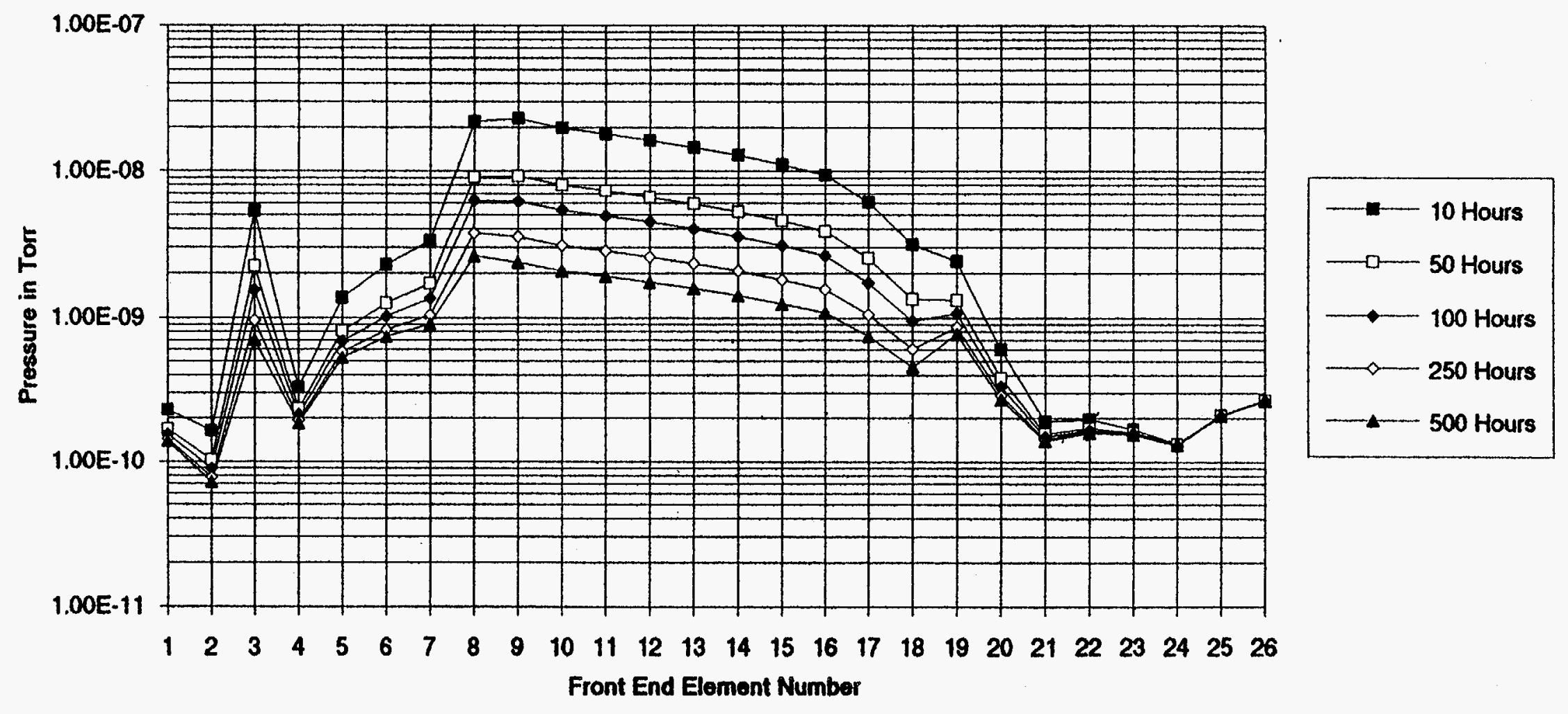


Windowless ID Front End Vacuum Profile With 1\% Beam on FM1, 1\% Beam on FM2,\& 3\% Beam on Shutter 2. Remainder of Beam to User.

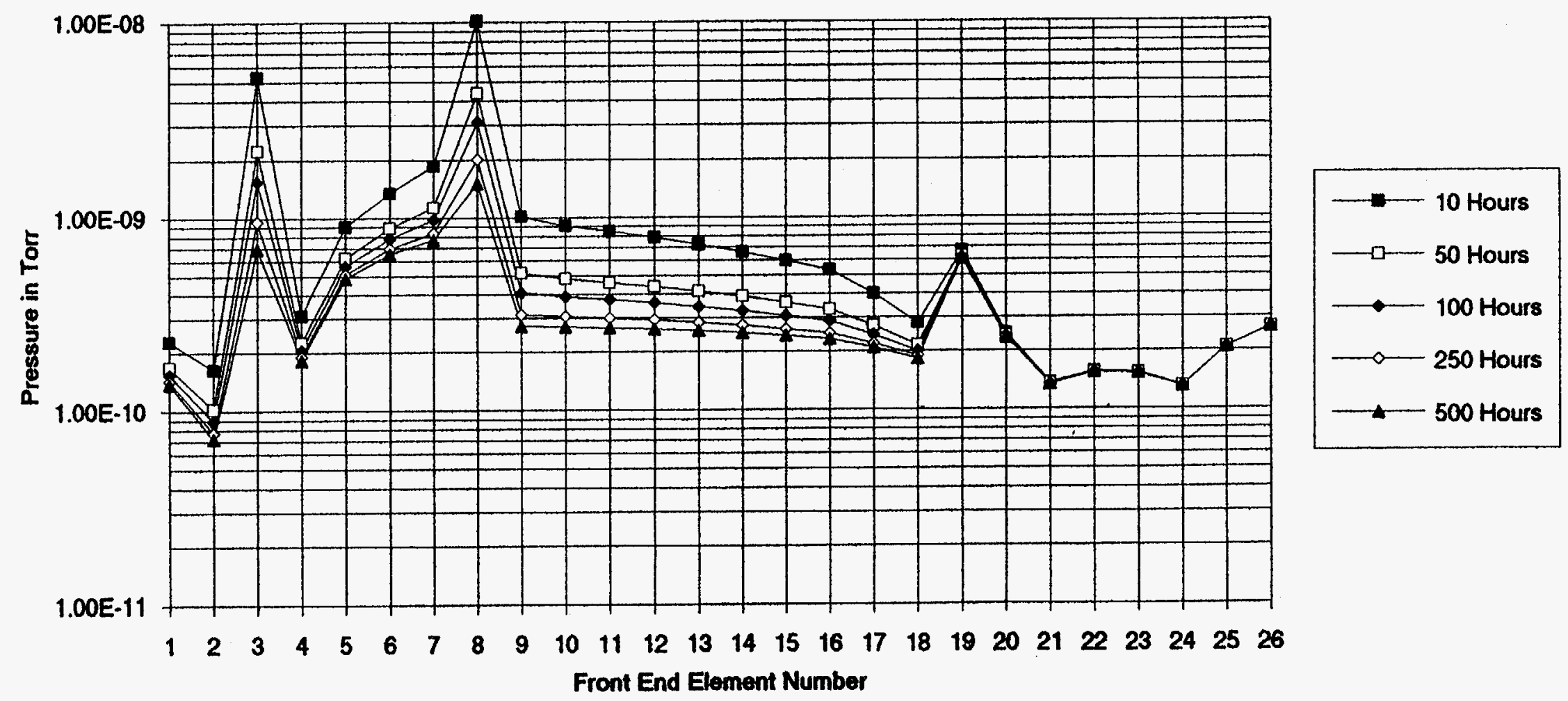



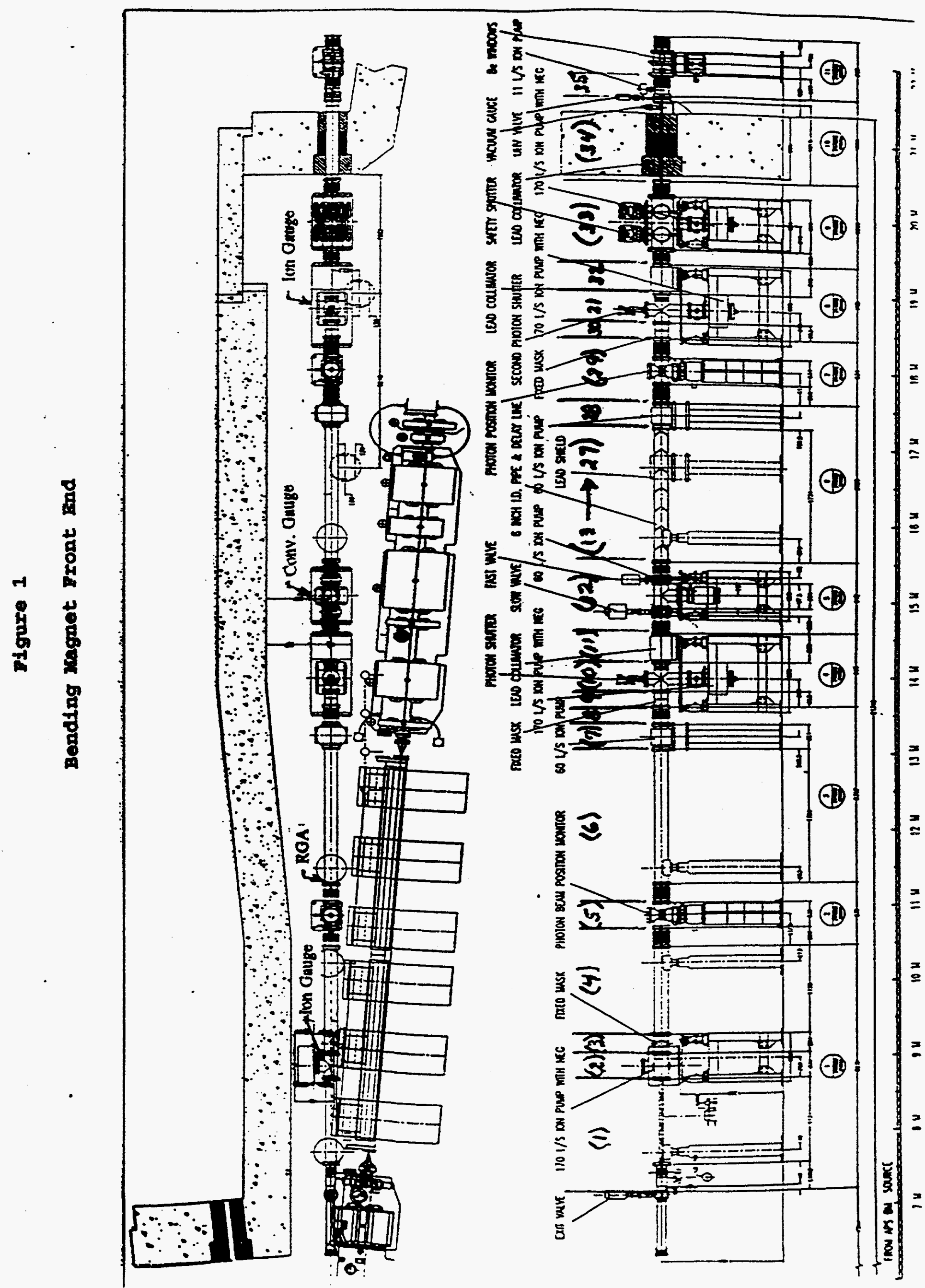


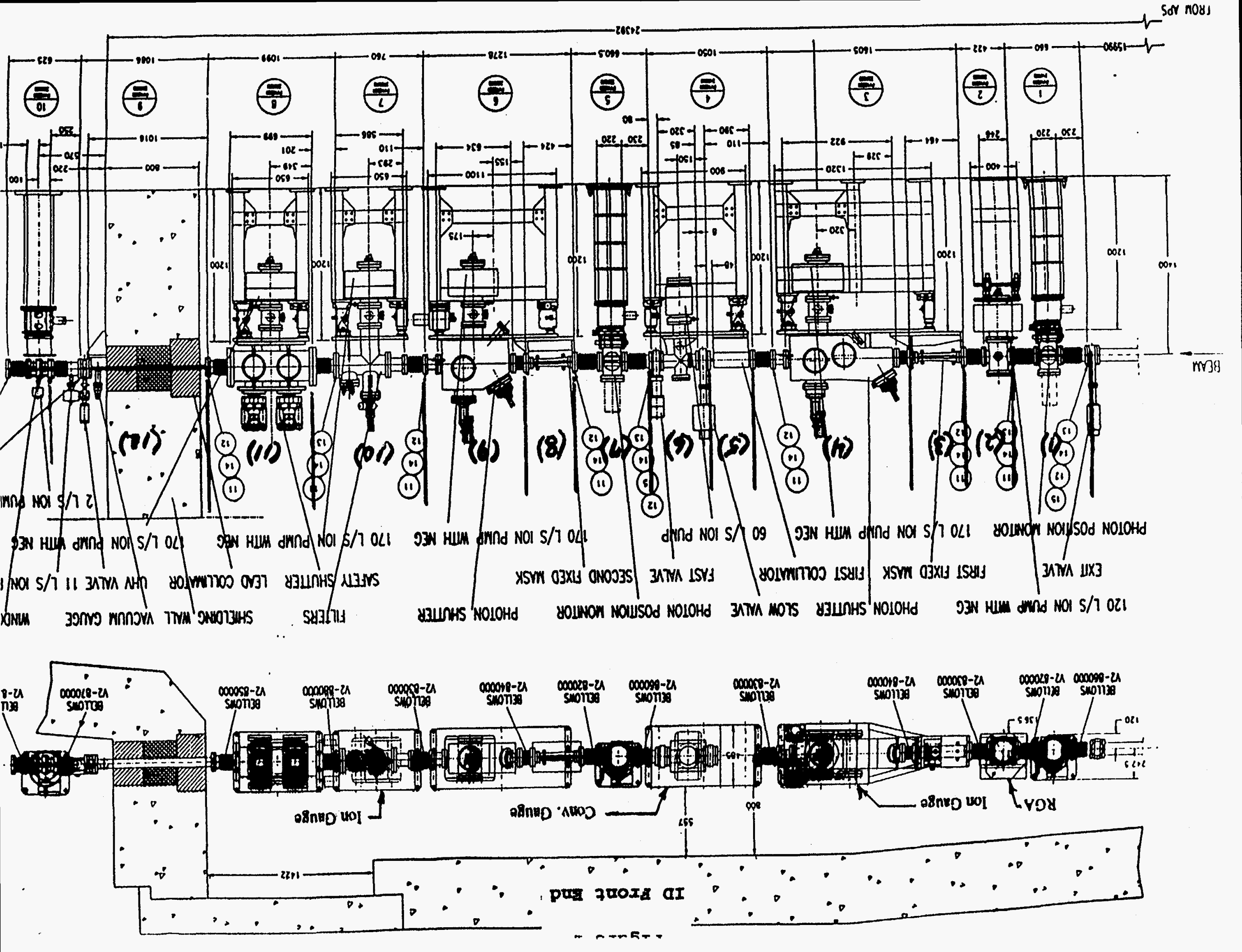


些

要

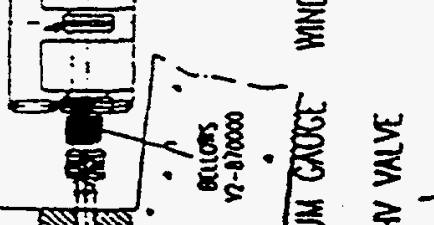
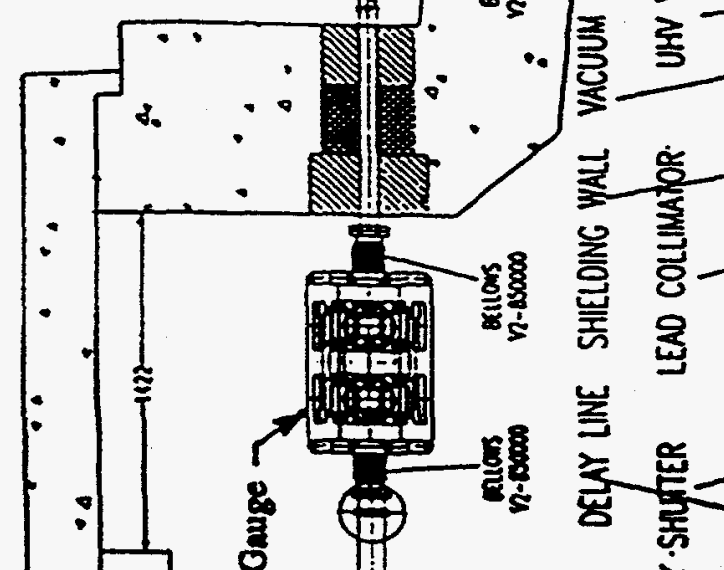

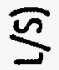

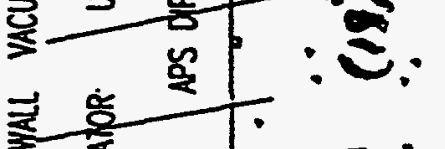

(-1) 8

$x$ \%

$\approx \omega$

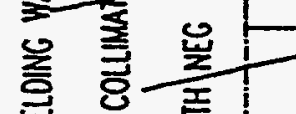

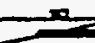

....

(a)

$x$

$7 \approx$

की

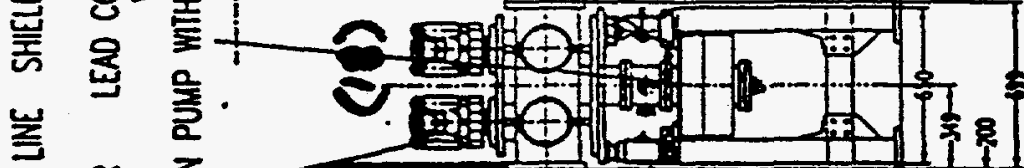

(Ai) $\frac{1}{5}=\sum$

岁突悹

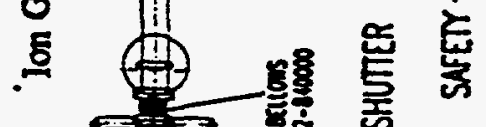

s

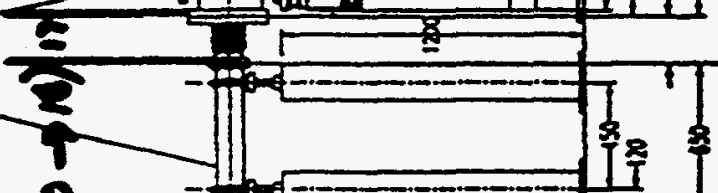

(1) $\Rightarrow$

z

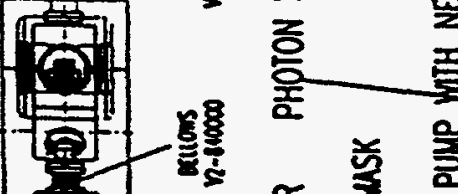

11

18 量

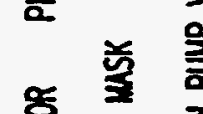

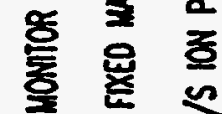

은 웅 응

舟

疍

म一

응

을 峛 홓

$-2$

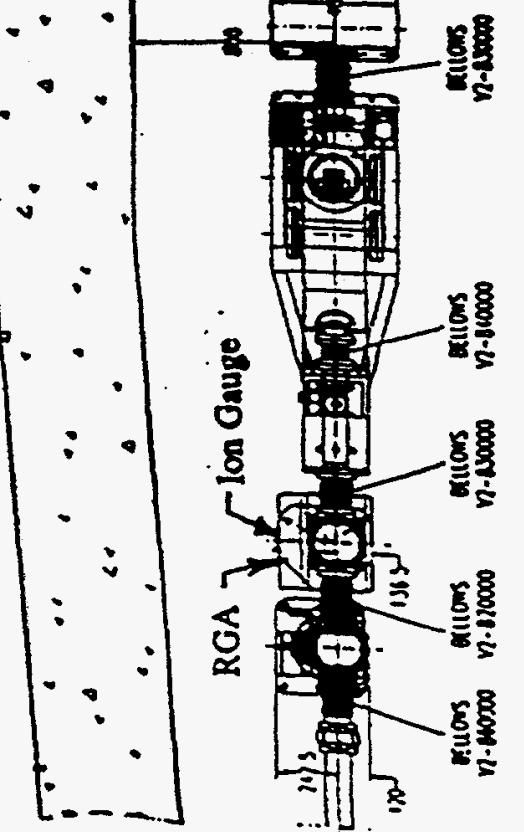

害 总

䒿点

8

そ

흥 旁

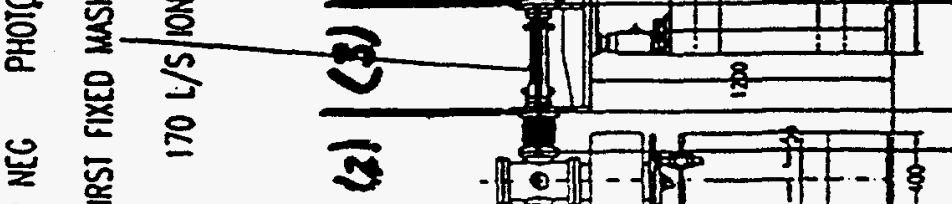

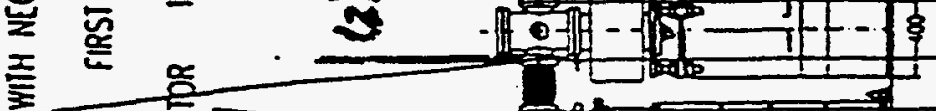

气

(12)

(Ai) $\frac{1}{2} \sum_{\mathrm{Z}}$

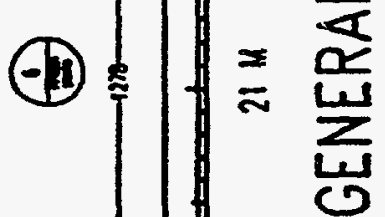

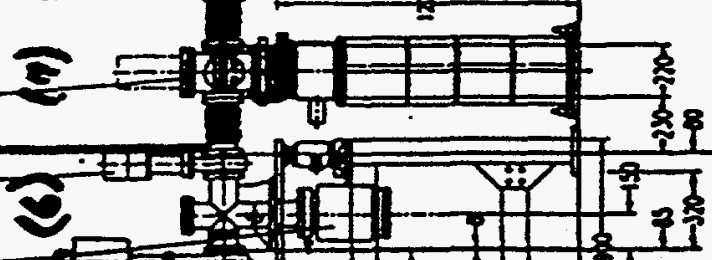

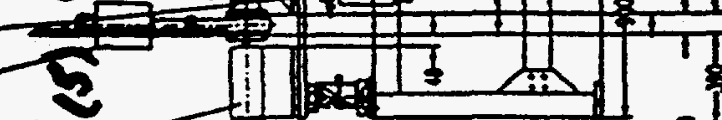

8

$=\alpha$

은

U

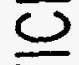

(-11) $\frac{5}{T} \cong 0$

$Z$
$=\frac{Z}{\Sigma}$
$=\underline{Z}$

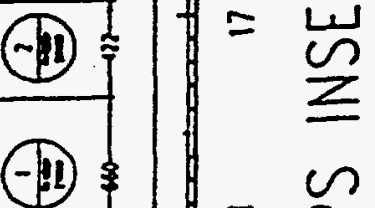

증 해 흔

흥

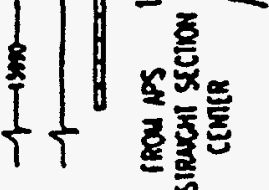




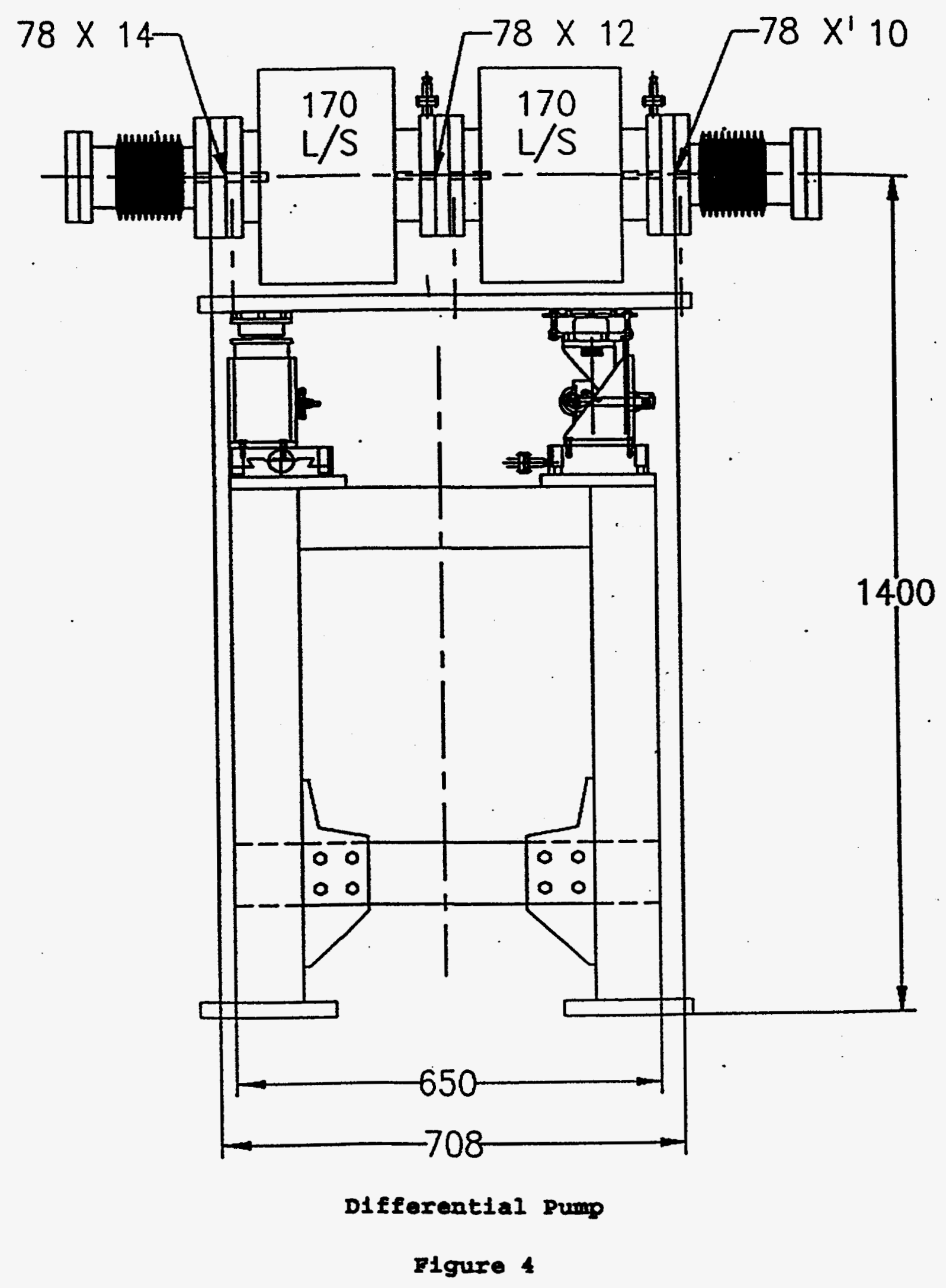




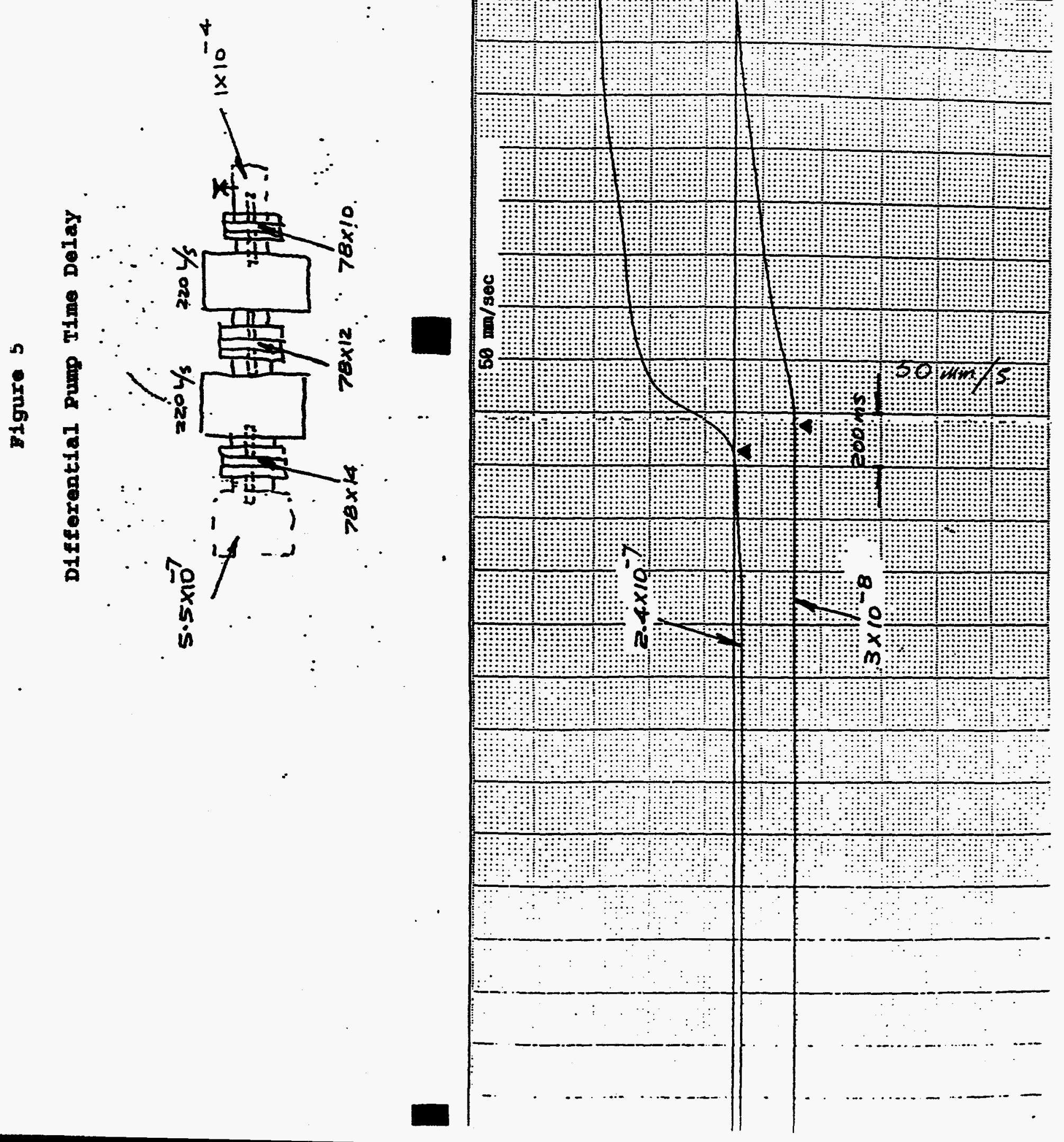


PHOTON BPM 1

FIXED MASK 1

PHOTON SHUTIER 1

LEAD COLUMATOR 1

PHOTON BPH 2

FIXED MASK 2

PHOTON SHUTTER 2

FILTERS

SAFETY SHUTIER

LEAD COLUMATOR 3

: HINDOW

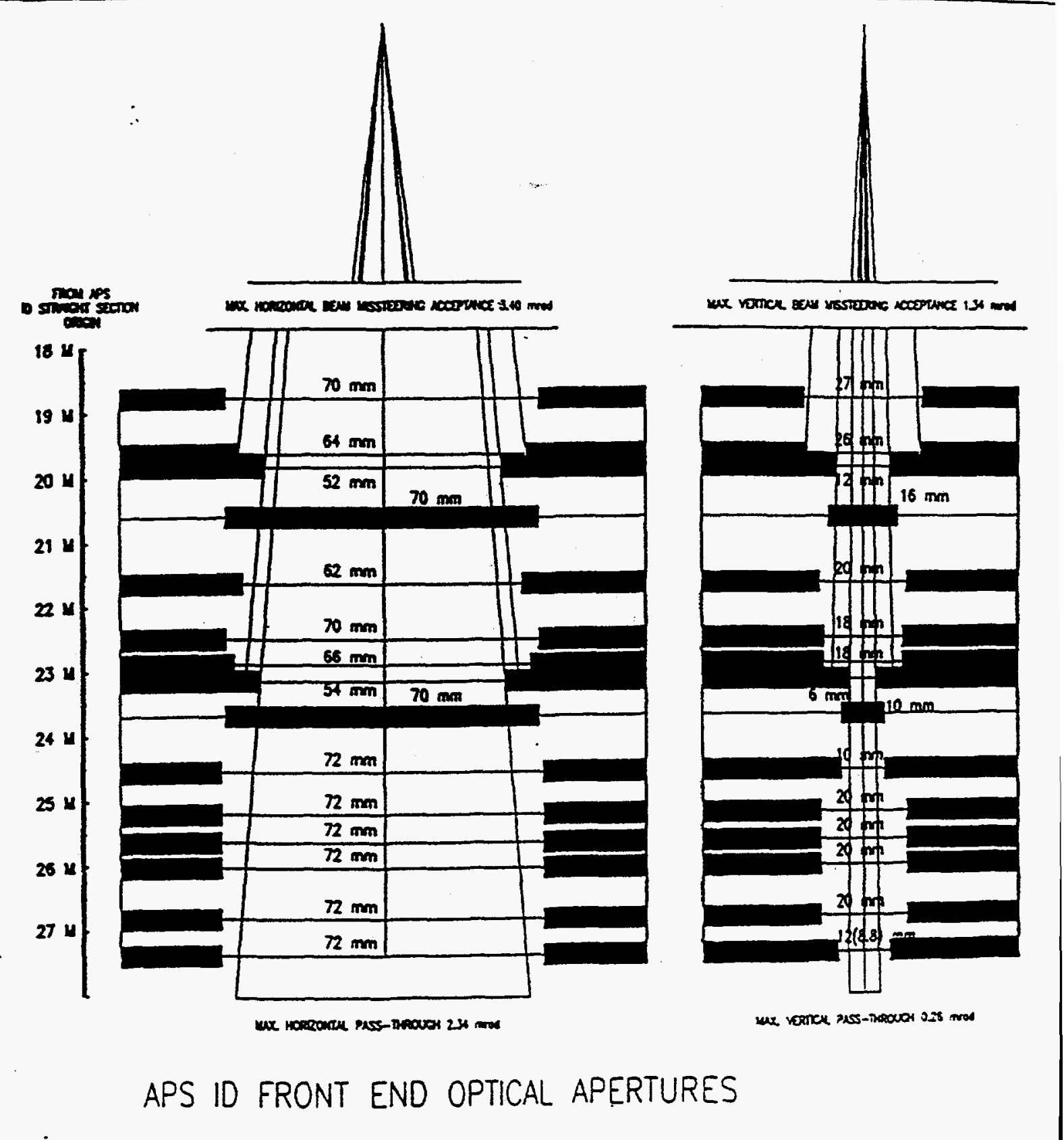

Etgure 6 
PHOTON BPM 1

FIXED MASK 1

PHOTON SHUTIER 1

LEAD COUMMATOR 1

PHOTON BPM 2

FXED MASK 2

PHOTON SHUTIER 2

FILTERS

SAFETY SHUTTER

LEAD COLLIMATOR 3

WINDOW

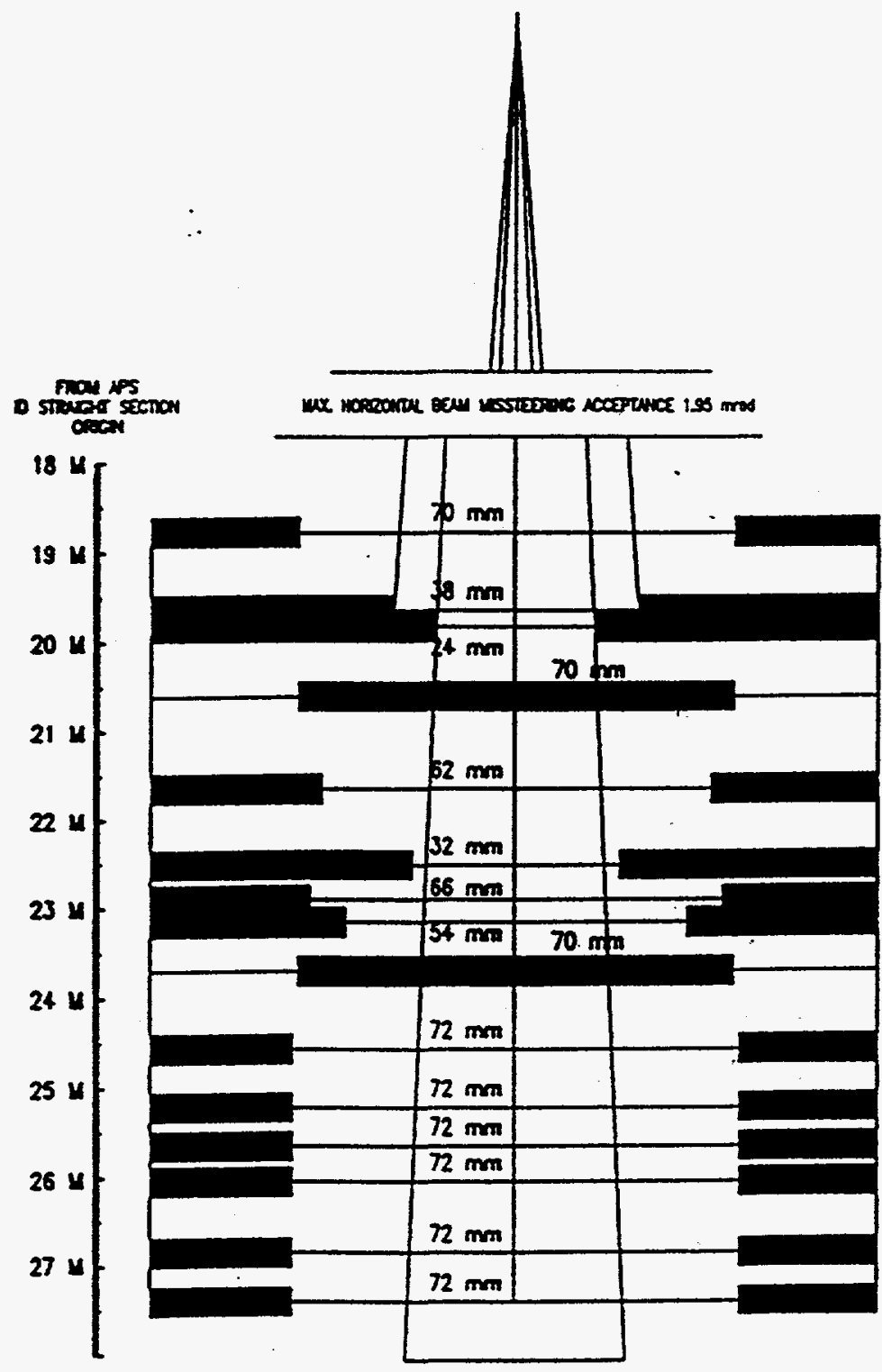

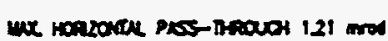

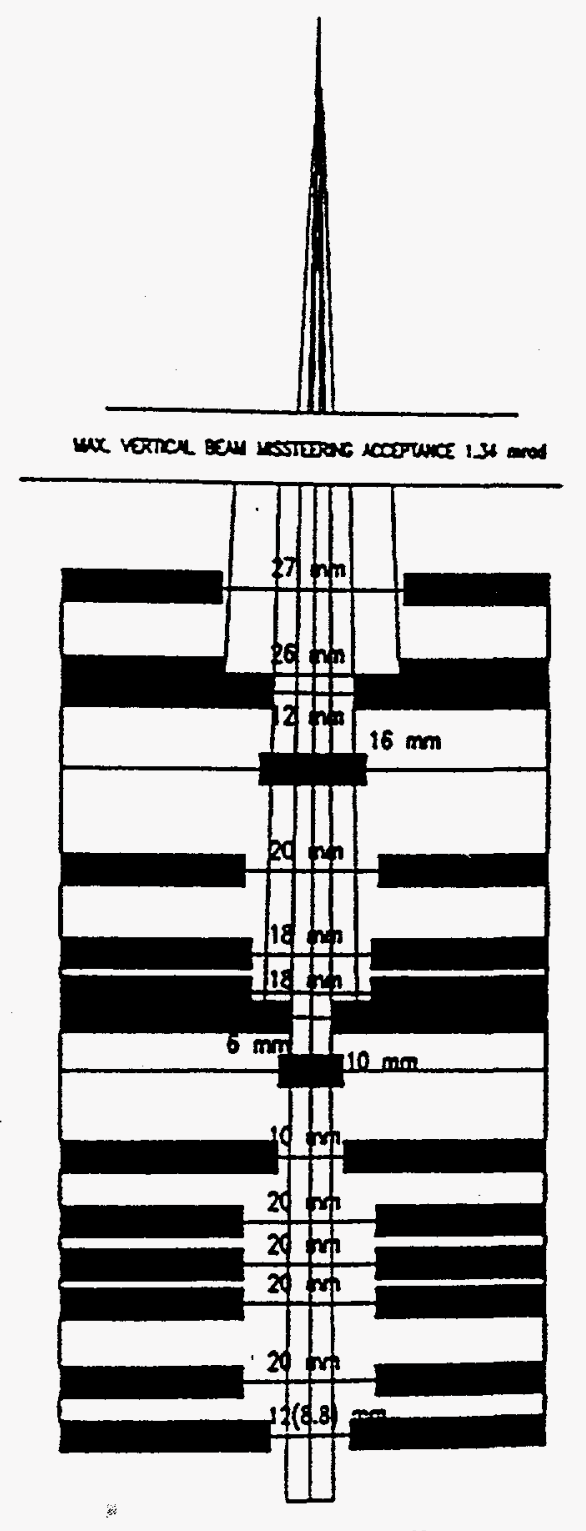

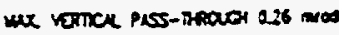

OPTICAL APERTURES FOR APS UNDULATOP. FRONT END 


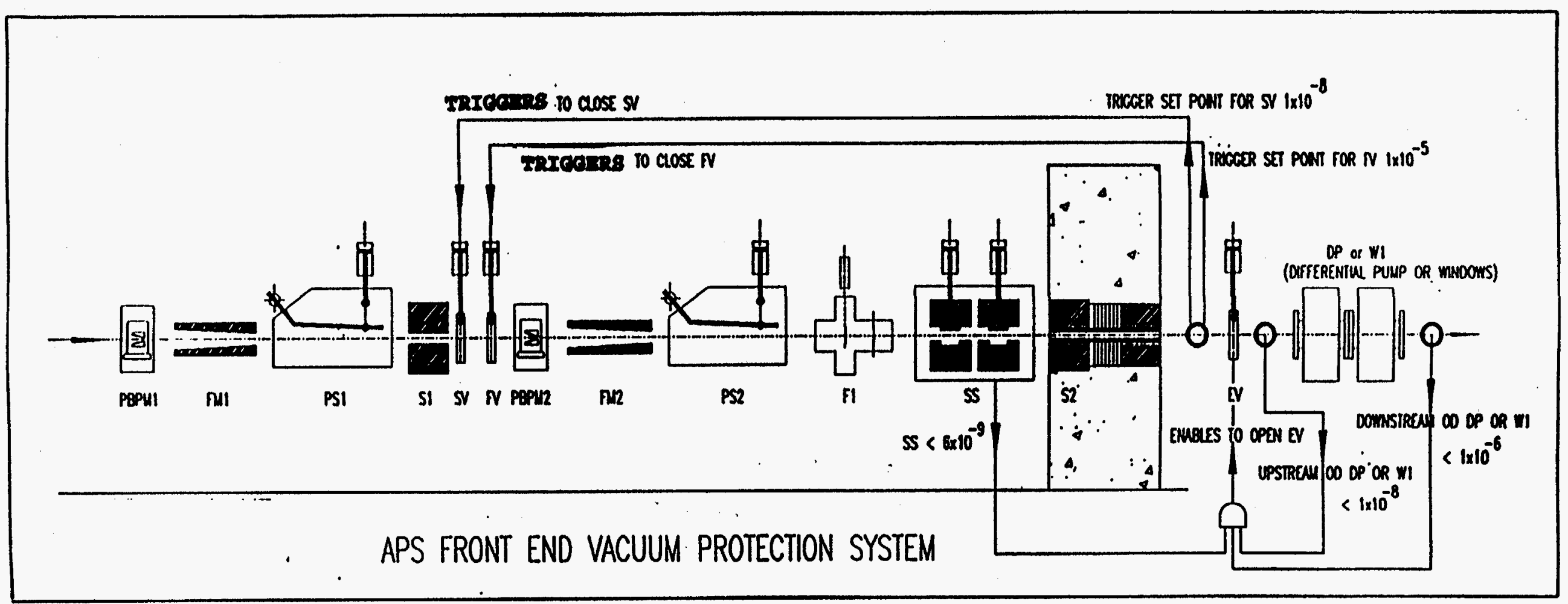

Pigure 8 

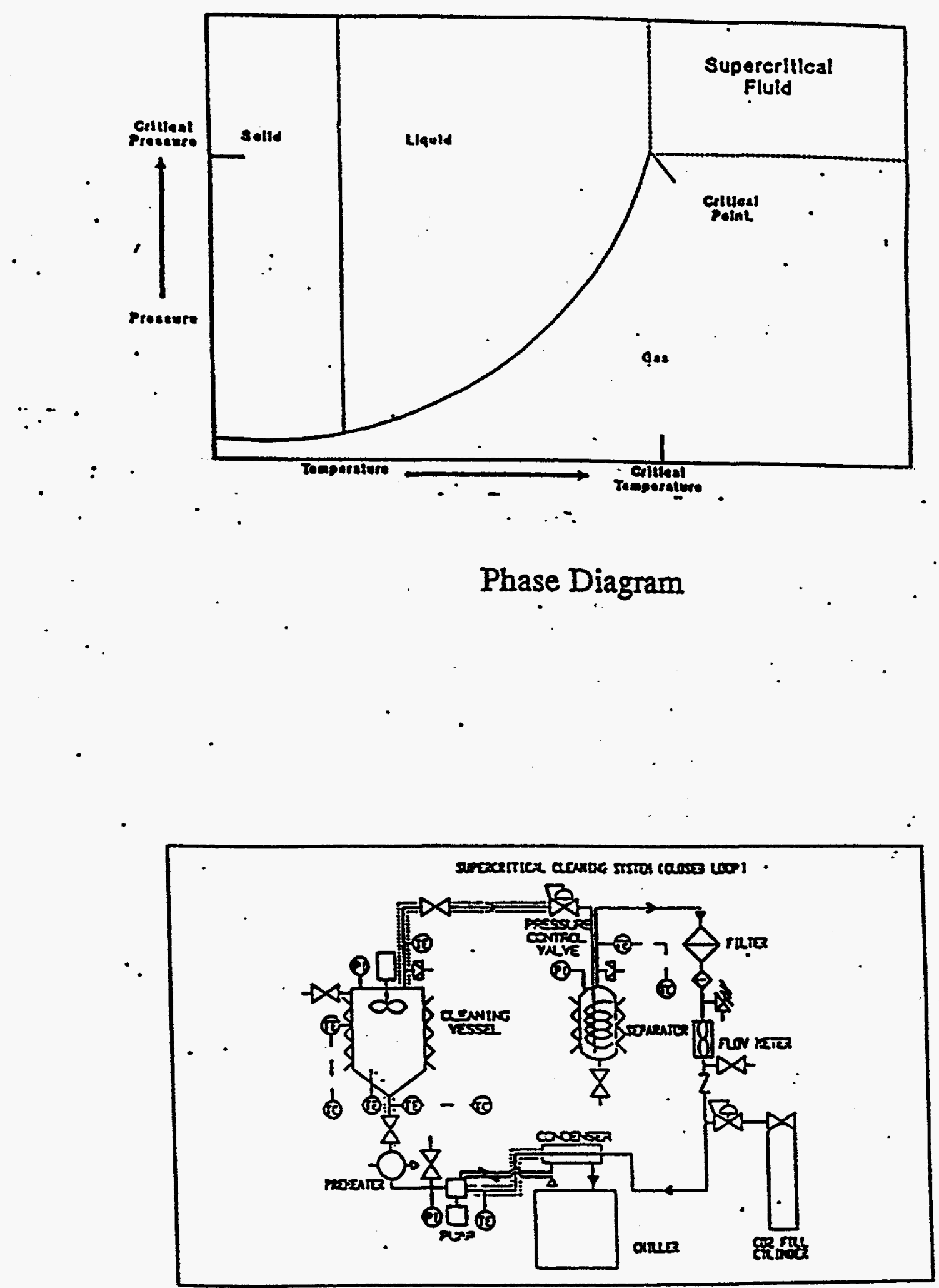

Supercritical Cleaning System. 


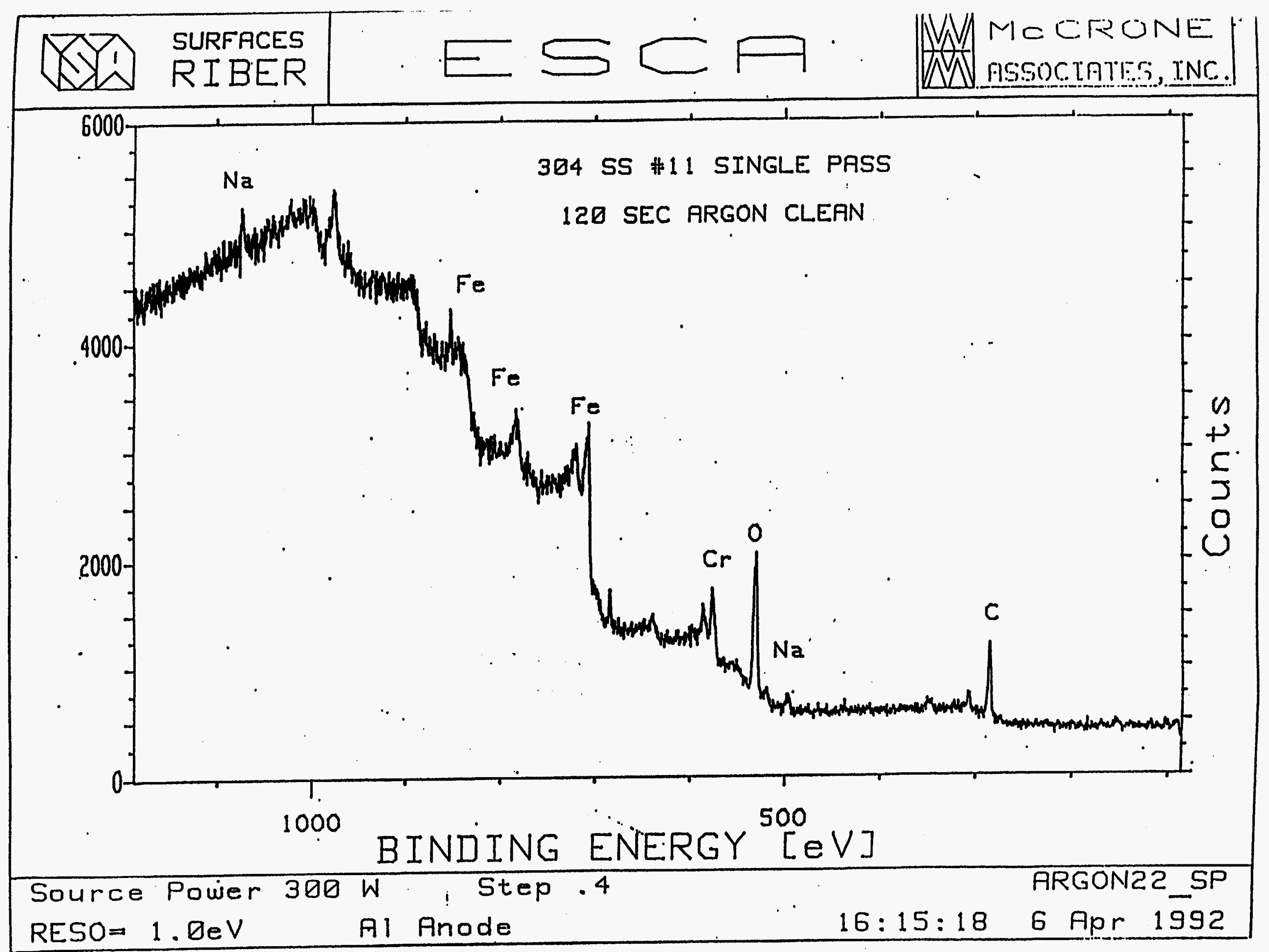

Btalnless steal IsCA Profile 


\section{Elemental Atomic Percentages on Sample Surfaces-}

\begin{tabular}{|c|c|c|c|c|c|c|c|c|c|c|}
\hline Material & Cleaning Data & Fe & $\mathrm{Ni}$ & Cu & $C_{r}$ & 0 & C & $\mathrm{Ca}_{2}$ & $\mathrm{Na}$ & Si \\
\hline 304 SS \#14 & Uncleaned & & & & & 43.1 & 51.1 & & 5.7 & \\
\hline $\begin{array}{l}304 \text { SS \#11 } \\
\text { Run } 1 \\
3500 \text { psi }\end{array}$ & $\begin{array}{l}\text { SCC Single Pass } \\
\text { SCC Single Pass } 30 \text { Arg. Cl. } \\
\text { SCC Single Pass } 120 \text { Arg. Cl. }\end{array}$ & $\begin{array}{l}15.3 \\
34.5 \\
43.8\end{array}$ & $\begin{array}{l}5.2 \\
5.6\end{array}$ & & $\begin{array}{r}13 \\
16.2 \\
13.6\end{array}$ & $\begin{array}{r}49 \\
30.9 \\
26\end{array}$ & $\begin{array}{r}19.1 \\
10.3 \\
7.2\end{array}$ & 1.3 & $\begin{array}{l}3.6 \\
2.9 \\
2.4\end{array}$ & \\
\hline $\begin{array}{l}304 \text { SS \#12, } \\
\text { Run } 2 \\
2000 \text { psi }\end{array}$ & $\begin{array}{l}\text { SCC Single Pass } \\
\text { sCC Single Pass } 30 \mathrm{Arg} . \mathrm{Cl} \text {. } \\
\text { SCC Single Pass } 120 \mathrm{Arg} . \mathrm{Cl} \text {. }\end{array}$ & $\begin{array}{r}18 \\
33.6 \\
40.8\end{array}$ & $\begin{array}{l}1.2 \\
4.5 \\
5.5\end{array}$ & & $\begin{array}{l}10.5 \\
14.2 \\
15.4\end{array}$ & $\begin{array}{l}46.6 \\
31.3 \\
27.8\end{array}$ & $\begin{array}{r}20.2 \\
10.6 \\
7.3\end{array}$ & $\begin{array}{l}0.1 \\
1.1 \\
0.7\end{array}$ & $\begin{array}{l}3.4 \\
4.7 \\
2.5\end{array}$ & \\
\hline 304 SS \#15 & $\begin{array}{l}\text { Chemical Clean } \\
\text { Chemical Clean } 30 \text { Arg. Cl. }\end{array}$ & $\begin{array}{l}42.2 \\
48.6\end{array}$ & $\begin{array}{l}5.1 \\
6.5\end{array}$ & & $\begin{array}{l}15.9 \\
14.5\end{array}$ & $\begin{array}{r}30 \\
29.4\end{array}$ & $\begin{array}{r}5.6 \\
1\end{array}$ & - & 1.1 & \\
\hline \multirow{2}{*}{$\begin{array}{l}304 L \text {. SS } \\
\$ 24\end{array}$} & Uncleaned & $\cdot$ & - & & & 35.5 & 64.5 & & & \\
\hline & Uncleaned $120 \mathrm{Arg} . \mathrm{Cl}$. & - & & & & 19.9 & 72.1 & & 8 & - \\
\hline $\begin{array}{l}304 \text { L SS } \\
\# 21\end{array}$ & SCC Single Pass & & & & & 57.1 & 31.9 & & 11 & \\
\hline $\begin{array}{l}\text { Run } 1 \\
3500 \text { psi }\end{array}$ & $\begin{array}{l}\text { SCC Single Pass } 30 \mathrm{Arg} . \mathrm{Cl} \\
\text { SCC Single Pass } 120 \mathrm{Arg} . \mathrm{Cl} \text {. }\end{array}$ & $\begin{array}{l}35.2 \\
38.9\end{array}$ & $\begin{array}{l}4.7 \\
5.7\end{array}$ & & $\begin{array}{l}11.6 \\
13.5\end{array}$ & $\begin{array}{l}31.6 \\
29.6\end{array}$ & $\begin{array}{r}12.1 \\
6.3\end{array}$ & $1.6^{\circ}$ & $\begin{array}{l}4.8 \\
4.4\end{array}$ & \\
\hline $\begin{array}{l}304 L \text { SS } \\
\# 23\end{array}$ & scc Single Pass & 12.8 & 1.6 & & 9.9 & 52.4 & 19.2 & & 4.1 & \\
\hline $\begin{array}{l}\text { Run } 2 \\
2000 \text { psi }\end{array}$ & $\begin{array}{l}\text { SCC Single Pass } 10 \text { Arg. Cl. } \\
\text { SCC Single Pass } 30 \mathrm{Arg} . \mathrm{Cl} \\
\text { SCC Single Pass } 120 \mathrm{Arg} . \mathrm{Cl} \text {. }\end{array}$ & $\begin{array}{l}34.5 \\
38.9 \\
43.3\end{array}$ & $\begin{array}{l}4.7 \\
4.8 \\
5.2\end{array}$ & & $\begin{array}{r}9.1 \\
10.5 \\
14.7\end{array}$ & $\begin{array}{l}36.2 \\
30.2 \\
29.1\end{array}$ & $\begin{array}{r}12.3 \\
13.2 \\
5.5\end{array}$ & & $\begin{array}{r}3.2 \\
2.5 \\
2.2\end{array}$ & \\
\hline \multirow[t]{2}{*}{$\begin{array}{l}304 L \text { SS } \\
\# 25\end{array}$} & Chemical Clean & 31.2 & 4.2 & & 13.2 & 42.7 & 8 & 0.7 & & \\
\hline & Chemical Clean 30 Árg. Cl. & 50.6 & 6.4 & & 13.2 & 28.6 & 1.1 & & & \\
\hline OFHC 5 & Uncleaned & & & 65.4 & & 21.3 & 13.3 & & & \\
\hline $\begin{array}{l}\text { OFHC \#1 } \\
\text { Run } 1 \\
3500 \text { psi }\end{array}$ & $\begin{array}{l}\text { SCC Single Pass } \\
\text { SCC Single Pass } 30 \mathrm{Arg} . \mathrm{Cl} \text {. } \\
\text { SCC Single Pass } 120 \mathrm{Arg} . \mathrm{Cl} \text {. }\end{array}$ & & & $\begin{array}{r}49 \\
86.2 \\
91.6\end{array}$ & & $\begin{array}{r}30.6 \\
8.3 \\
4.3\end{array}$ & $\begin{array}{r}12.9 \\
5.5 \\
4.1\end{array}$ & & - & 7. \\
\hline $\begin{array}{l}\text { OFHC } \\
\text { Run } 2 \\
2000 \text { psi }\end{array}$ & $\begin{array}{l}\text { SCC Single Pass } \\
\text { SCC Single Pass } 30 \mathrm{Arg} . \mathrm{Cl} \text {. } \\
\text { SCC Single Pass } 120 \mathrm{Arg} . \mathrm{Cl} \text {. }\end{array}$ & & & $\begin{array}{l}60.5 \\
91.2 \\
94.4\end{array}$ & & $\begin{array}{r}27.9 \\
6 \\
3.8\end{array}$ & $\begin{array}{r}11.6 \\
2.8 \\
1.9\end{array}$ & & & \\
\hline
\end{tabular}

Material Cleaning Data

$\begin{array}{lllllllll}\mathrm{Fe} & \mathrm{Ni} & \mathrm{Cu} & \mathrm{Cr} & \mathrm{O} & \mathrm{C} & \mathrm{Ca} & \mathrm{Na} & \mathrm{Si}\end{array}$ 


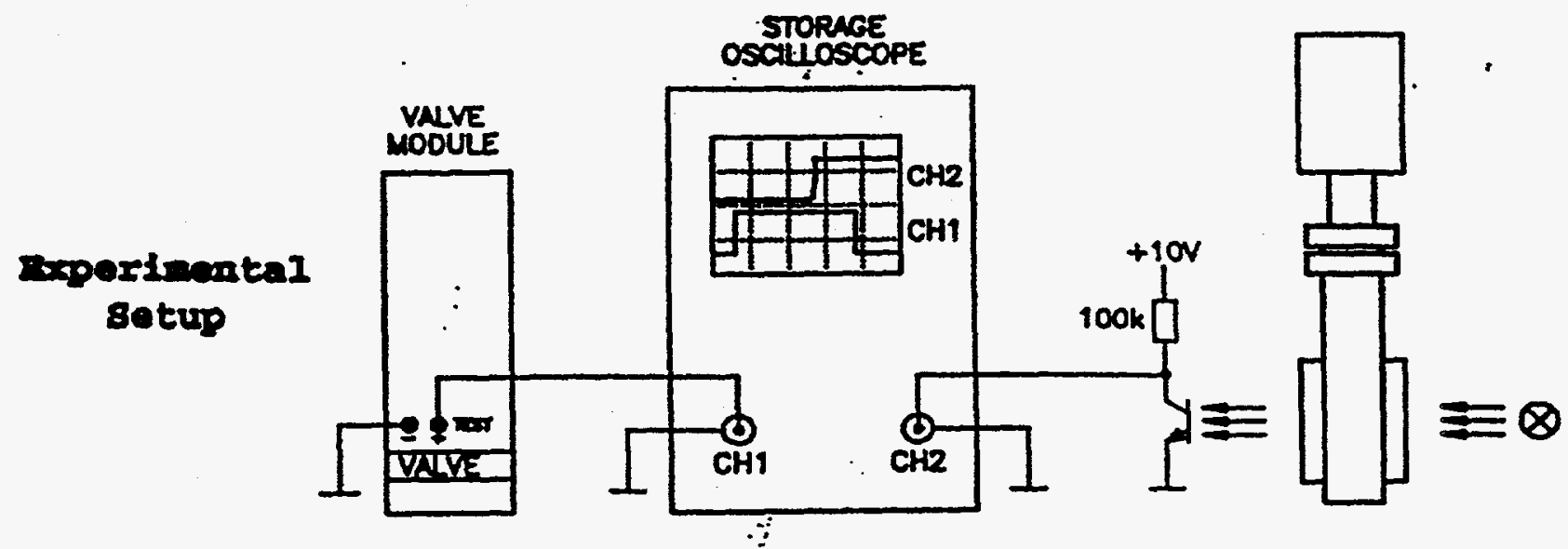

Dush Button Irtggexed

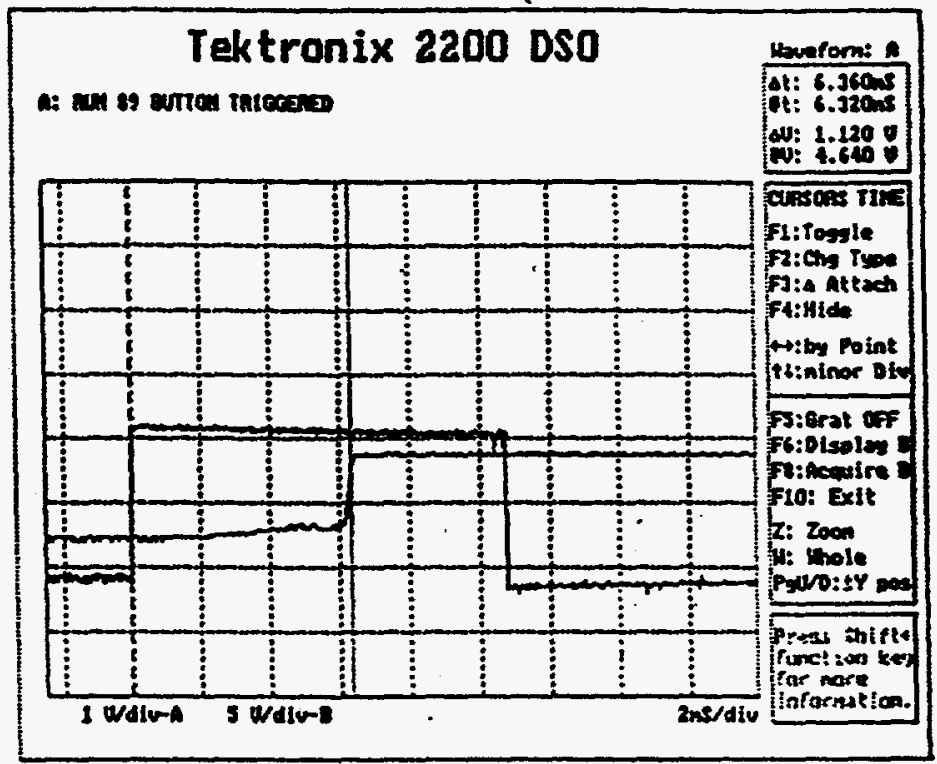

Vacuma Ixiggered

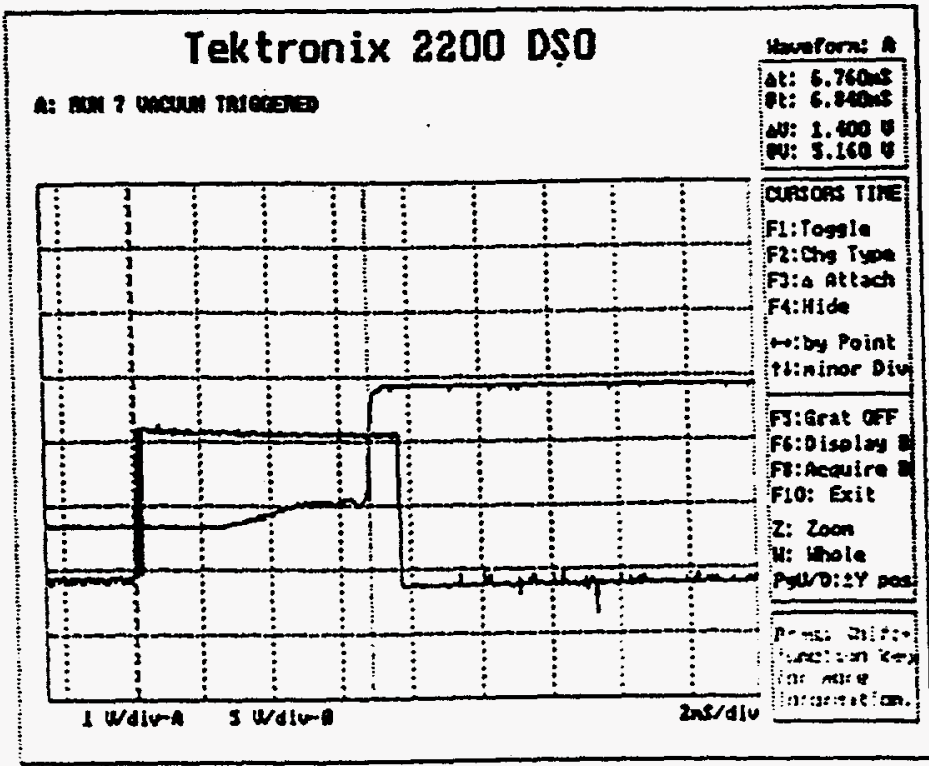

past Valve Closing Time 